\title{
The spread of breathing air from wind instruments and singers using schlieren techniques
}

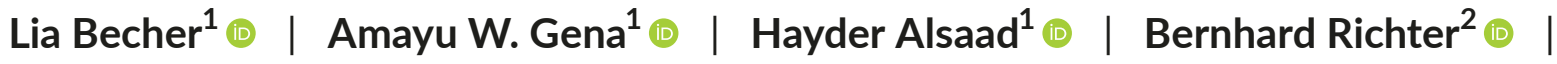 \\ Claudia Spahn ${ }^{2} \odot$ | Conrad Voelker ${ }^{1} \odot$
}

${ }^{1}$ Department of Building Physics, Bauhaus-University Weimar, Weimar, Germany

${ }^{2}$ Freiburg Institute for Musicians' Medicine, Medical Faculty University Freiburg and Freiburg University of Music, Freiburg, Germany

\section{Correspondence}

Lia Becher, Department of Building Physics, Bauhaus-University Weimar, Coudraystr. 11A, 99423 Weimar, Germany.

Email: lia.becher@uni-weimar.de

Funding information German Research Foundation DFG, Grant/Award Number: 444059583

\begin{abstract}
The spread of breathing air when playing wind instruments and singing was investigated and visualized using two methods: (1) schlieren imaging with a schlieren mirror and (2) background-oriented schlieren (BOS). These methods visualize airflow by visualizing density gradients in transparent media. The playing of professional woodwind and brass instrument players, as well as professional classical trained singers were investigated to estimate the spread distances of the breathing air. For a better comparison and consistent measurement series, a single high note, a single low note, and an extract of a musical piece were investigated. Additionally, anemometry was used to determine the velocity of the spreading breathing air and the extent to which it was quantifiable. The results showed that the ejected airflow from the examined instruments and singers did not exceed a spreading range of $1.2 \mathrm{~m}$ into the room. However, differences in the various instruments have to be considered to assess properly the spread of the breathing air. The findings discussed below help to estimate the risk of cross-infection for wind instrument players and singers and to develop efficacious safety precautions, which is essential during critical health periods such as the current COVID-19 pandemic.
\end{abstract}

\section{KEYWORDS}

airborne infection, background-oriented schlieren, COVID-19 pandemic, schlieren imaging, singers, wind instruments

\section{1 | INTRODUCTION}

During critical periods such as the current coronavirus disease 2019 (COVID-19) pandemic, musicians have to mind not only restrictions such as social distancing and hygienic precautions, but also suffer as concerts are often not allowed. One reason is the fear that wind instruments and singers might spread enormous amounts of contaminated breathing air into the room and, therefore, can be a risk for transmitting SARS-CoV-2 (severe acute respiratory syndrome coronavirus 2). This assumption was supported by investigations on increased infection risks during singing and choir rehearsals. ${ }^{1,2}$ To assess this risk, this paper presents empirical measurements giving an insight into how far the breathing air, which could contain infectious droplets or aerosols, spreads from different wind instruments (both woodwind and brass) and trained classical singers.

Recent studies investigated the distribution of droplets and aerosols as well as the escaping breathing air when breathing, speaking, and singing in enclosed spaces. ${ }^{3-6}$ According to the current state of knowledge, not only droplets with a size $>5 \mu \mathrm{m}$ but also aerosols with a size $<5 \mu \mathrm{m}^{7}$ are responsible for infections with the novel 
coronavirus SARS-CoV-2. ${ }^{8}$ While larger droplets with a size of approximately $100 \mu \mathrm{m}$ fall to the ground within few seconds and being transported approximately $1.5 \mathrm{~m}$ into the room, ${ }^{9}$ smaller aerosols can remain longer in the room air and, therefore, pose a risk for room occupants. ${ }^{10}$ However, for singing, several studies claimed that at a distance of $0.5 \mathrm{~m}$ in front of the mouth almost no airflow can be depicted with professional singers. By placing a burning candle at $0.5 \mathrm{~m}$ in front of the singer's mouth, it was observed that the flame hardly moved due to only small disturbances of the exhaled air. ${ }^{11,12}$ For playing wind instruments, Spahn et al. ${ }^{13}$ concluded that the air escaping from either the bell, the tone holes, or the mouthpiece of the instruments does not move farther than $1.5 \mathrm{~m}$. For wind instruments, the exhalation of air is similar to singing: the aim is to use as little as possible breathing air to allow the vocal cords (singing), reeds (woodwind), or the lips (brass) to vibrate and stimulate the air column inside the instrument. ${ }^{11}$

To empirically assess the aerosol concentration in enclosed spaces, Nusseck et al. measured the carbon dioxide concentration $\left(\mathrm{CO}_{2}\right)$ as an indicator of indoor air quality when playing wind instruments and singing. The results showed that the $\mathrm{CO}_{2}$ emission is similar to light and moderate activities. ${ }^{14}$ Further investigations from Muerbe et al. ${ }^{3}$ who counted the particles emitted during professional singing, showed that the emission of aerosols is much higher when singing than when speaking or breathing.

The present study investigates the spread of breathing air from wind instruments and singers using flow visualization and anemometry measurements. While anemometry provided the flow velocity of the escaping air, flow visualization was used to determine the spread of the expelled air. Two flow visualization methods were used: (1) schlieren imaging with a schlieren mirror and (2) backgroundoriented schlieren (BOS).

The schlieren imaging method and the BOS method visualize density gradients due to differences in temperature or pressure in transparent media non-invasively and with no distortion in the flow field. As the warm breathing air cools down while going through the instrument and spreading into the room, highly precise schlieren setups are needed to visualize these small density gradients.

Within building and health science, schlieren imaging with a schlieren mirror has been used for the qualitative investigation of the airflow supplied by personalized ventilation, ${ }^{15}$ to investigate the propagation of the breathing air when wearing masks ${ }^{16}$ or during sneezing, ${ }^{17}$ or to determine the dispersion and distribution characteristics of the exhaled airflow for prediction of disease transmission. ${ }^{18,19}$ While schlieren imaging simultaneously produces high-resolution images depending on the frame rate, the measurement field is restricted to the size of the mirror. ${ }^{20}$ Since the spread of breathing air may exceed this distance, BOS was used in further investigations to avoid these spatial restrictions. BOS as a relatively young visualization method ${ }^{21}$ is used in numerous fields, such as the visualization of open-air explosions, ${ }^{22}$ three-dimensional reconstruction of large-scale blade-tip vortices of a flying helicopter, ${ }^{23}$ and instantaneous three-dimensional density field reconstruction. ${ }^{24}$

\section{Practical implications}

- Using optical methods like schlieren imaging and background-orientedschlieren, airflow can be visualized to determine the direct risk of potentially infectious breathing air escaping from wind instruments and singers.

- To determine the spread of breathing air from wind instruments, the air escaping from the bell of the instruments (both woodwind and brass instruments), as well as the air escaping from the tone holes, the mouthpiece, and mouth of the musician during various activities (woodwind only) have to be taken into consideration.

- The findings contribute to understanding the spread of breathing air that could contain infectious droplets or aerosols when playing wind instruments or singing, which is essential in critical health periods like the COVID-19 pandemic.

- The results of the non-invasive schlieren methods help to develop efficacious safety precautions for both musicians and the audience.

It should be noted that the results presented in this article do not show the actual dispersion of particles but only the dispersion of the breathing air, which might contain infectious particles. Therefore, the evaluations can only be used to determine how far and to which extent the expelled air is transported directly into the room. Here, the spreading distance is determined by the velocity and the diameter of the outlet. ${ }^{9}$ The evaluations shown in this article can be used as a guideline to ascertain how far the breathing air containing potentially infectious particles reaches into the room.

\section{2 | VISUALIZATION METHODS}

The breathing air was visualized using the optical, non-invasive schlieren imaging with the schlieren mirror and the BOS method. Both methods allow visualizing density gradients in transparent media. These density gradients are based on differences in temperature or pressure and cause differences in the refractive index of the fluid that lead to the light rays changing their speed and, therefore, refract. These refractions result in discontinuous movement, ${ }^{25}$ which appears as schlieren, a German word meaning streaks. ${ }^{26}$

However, as the breathing air that escapes from the mouth of the musicians or the wind instruments has a higher temperature or humidity (or both) than the surrounding air, the optical schlieren techniques allow visualizing these gradients. For some instruments that have a long or wide bore such as the $\mathrm{F}$ tuba, the air blown into the instrument cooled down when reaching the bell. Therefore, to visualize the breathing air escaping from the $F$ tuba, the instrument 
was played approximately 30 min before the test series to warm up the brass and consequently the air escaping the bell.

Figure 1 shows the experimental setups of both systems. The setup and principle of each system are described further in the following sections.

During the investigations, the room temperature was fairly constant at approximately $\theta \approx 23^{\circ} \mathrm{C}$. Heating, cooling, and ventilation systems were turned off. Additionally, the musician with the instrument being investigated and the present researches were asked to remain as still as possible during the measurements to avoid any disturbing airflows that could affect the measurement series.

\section{1 | Schlieren imaging}

The single-mirror coincident schlieren imaging system at the Department of Building Physics at the Bauhaus-University Weimar consists of a concave spherical mirror with astronomical qualities and a diameter of $1 \mathrm{~m}$, a light-emitting diode (LED) light source, a knife-edge schlieren cutoff, and a high-resolution digital camera (Canon EOS 5DS R) (Figure 1 left and Figure 2).

During the investigations, the schlieren object (musician with instrument or singer) is placed in front of the mirror. The diverging light ray emitted from the LED reaches the mirror and returns along the coincident path where it crosses the schlieren object, which is inducing the density gradient. For coincident optics, the schlieren object is traversed twice by the same light ray. Therefore, the distance between the light source and the knife-edge was kept at a minimum distance of $5 \mathrm{~mm}$ to avoid double imaging. When passing through the density gradients, some rays are refracted. If these rays are refracted downwards to the extent of $\Delta \varepsilon$, they are blocked by the knife-edge and, thus, create shadows in the image screen which constitutes the foreground of the schlieren image. The light rays that are refracted over the knife-edge to the extent of $\Delta a$ pass to the camera sensor and brighten the image screen which constitutes the background of the schlieren image. Further information about the principle of the schlieren imaging system can be found in Gena et al. ${ }^{20}$ In the experiments, the knife-edge was at a position where it blocks approximately $50 \%$ of the refracted light rays. Because of the low light level in the laboratory, the camera was set to a lens aperture of $\mathrm{f} / 2$, a shutter speed of $1 / 60 \mathrm{~s}$, and ISO 320 . To capture the density gradients in motion, 0.92 megapixels schlieren images (frame size $1280 \times 720$ pixels) were captured at 50 frames/s. This high frame rate allowed capturing still images as well as videos of the flow.

\section{2 | Background-oriented schlieren (BOS) method}

The BOS system consists of a structured background (randomly distributed black squared dots on a white surface), a high-resolution camera (Canon EOS 5DS R) focusing the background, and two flashlights illuminating the background pattern. For investigations, the schlieren object (musician with instrument or singer) is placed in front of the structured background (Figure 1 right and Figure 3).

For evaluation, two recordings of the background pattern are needed: one recording as a reference image of the undisturbed background (flow-off) and one recording of the density gradient in front of the background (flow-on). Due to the refractive index gradient, each light ray passing through the measuring field is refracted to the extent defined by the gradient (phase shift $\Delta y$ ). Hence, a pixel on the flow-on image appears at a different location compared to the reference image. Using cross-correlation algorithms, it is then possible to compare the intensity distributions of both images to determine the image shift of each pixel and, thus, to visualize the density gradient. Further information about the BOS method can be found in Becher et al. ${ }^{27}$

During the investigations, the camera was set to a lens aperture of $f / 14$, a shutter speed of $1 / 80 \mathrm{~s}$, and ISO 100 . To capture the density gradients in motion, 50.6 megapixels RAW schlieren images (frame size $8688 \times 5792$ pixels) were captured at 1.5 frames/s. Due to this low frame rate, no video recordings were made with the BOS method.

\subsection{Experimental scheme}

To investigate the spread of breathing air, two separate test series were conducted. In the first series, musicians from the philharmonic orchestra Thüringen Philharmonie Gotha-Eisenach, Germany were positioned in front of the schlieren mirror while playing their particular instrument. Since the visualization range of the schlieren mirror is limited to its $100 \mathrm{~cm}$ diameter, a second series of tests were conducted using the BOS method with musicians from the Deutsches Nationaltheater und Staatskapelle Weimar, Germany. This allowed capturing of the airflow to its full extent and to confirm the results which had been measured previously with the schlieren mirror. Additionally, in the second series of tests, air velocity measurements were conducted using omnidirectional hot-wire anemometers from the German company Ahlborn with an accuracy of $\pm 1.5 \%$ of the measured value, a measurement range of $0.01-1 \mathrm{~m} / \mathrm{s}$, and a

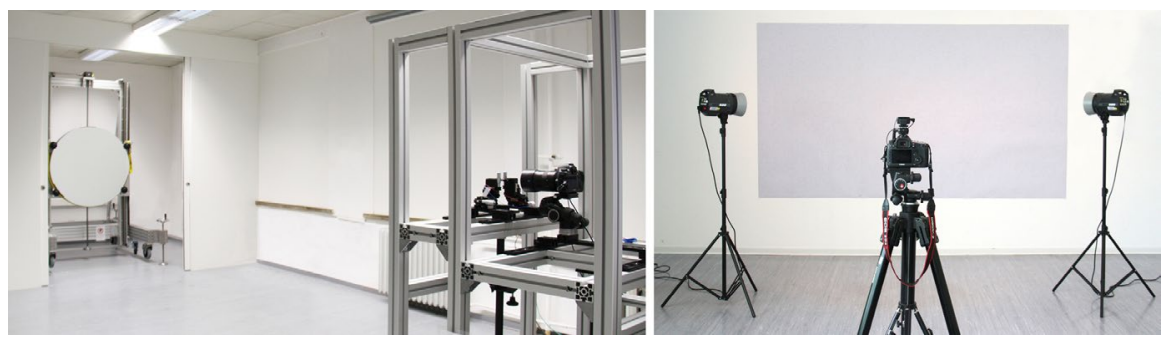

FIGURE 1 Setup of the single-mirror coincident schlieren system (left) and the BOS system (right) at the Department of Building Physics at the BauhausUniversity Weimar 


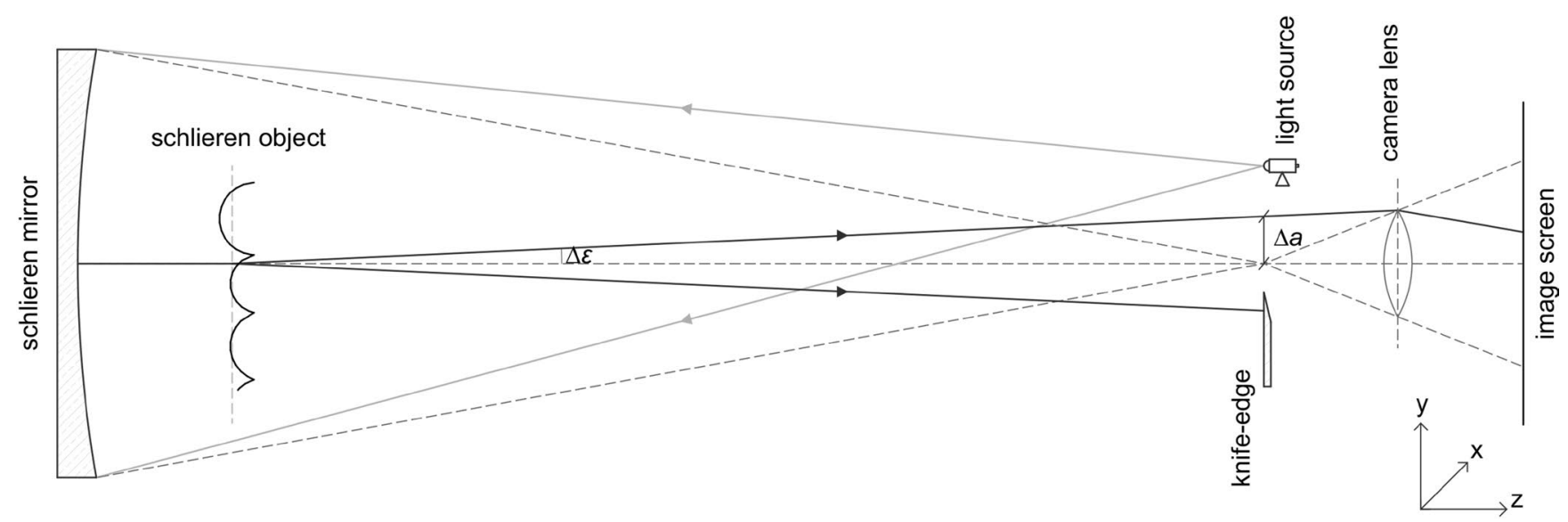

FIGURE 2 Schematic setup of the single-mirror coincident schlieren imaging system

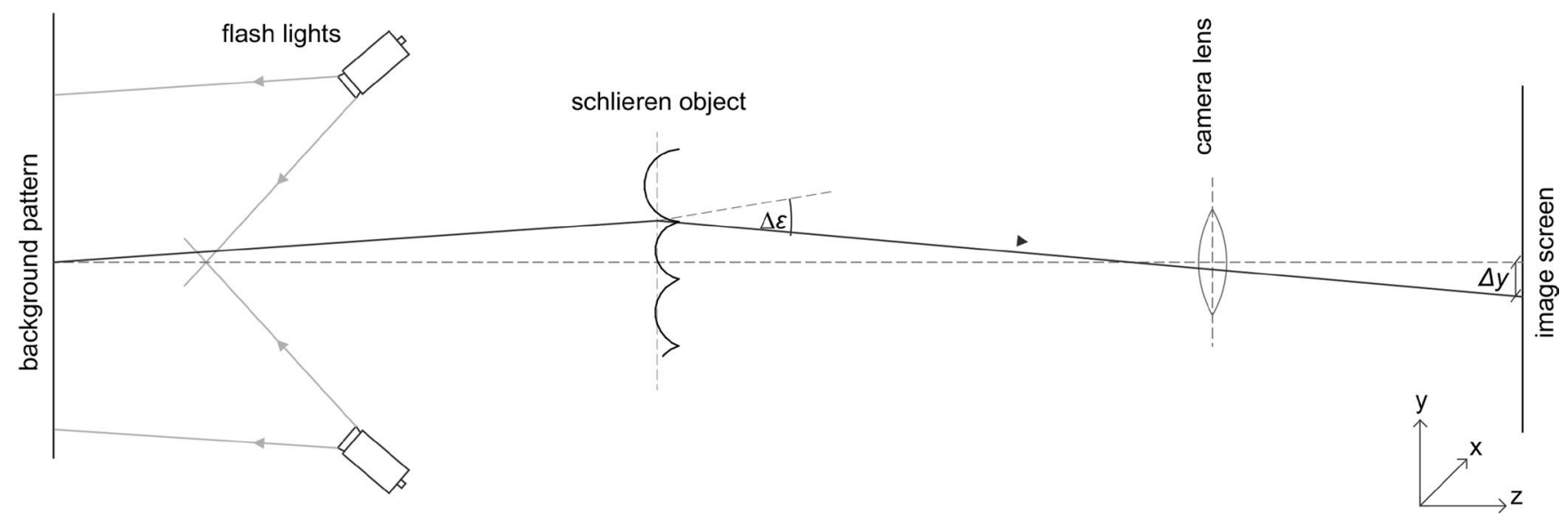

FIGURE 3 Schematic setup of the BOS system

resolution of $0.001 \mathrm{~m} / \mathrm{s}$. The air velocity was recorded over a measurement period of approximately $15 \mathrm{~s}$ (playing one note) and approximately $30 \mathrm{~s}$ (playing phrases of a musical piece or improvising) with a sampling interval of $1 \mathrm{~s}$ each; the collected values were then averaged. Only three sensors were used to not alter the flow at distances

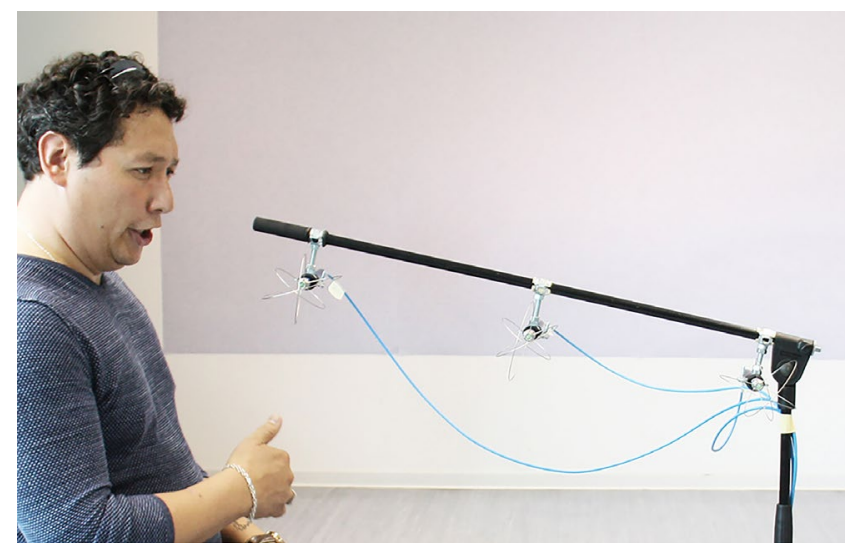

FIGURE 4 Baritone during the velocity measurements using omnidirectional hot-wire anemometry of $20,52.5$, and $85 \mathrm{~cm}$ in front of the instrument or mouth (Figure 4). A minimum possible distance of $20 \mathrm{~cm}$ was used to avoid possible damage to the sensors from unexpected movement of the subjects. From the schlieren mirror images, we concluded that $85 \mathrm{~cm}$ is a suitable distance for the farthest sensor. For each instrument, several measurements were conducted (bell, tone holes, mouthpiece, single notes, and musical piece/improvisation).

\section{\begin{tabular}{l|l}
3 & RESULTS
\end{tabular}}

In the following sections, the figures displayed in a round shape are recordings of the musicians in front of the round schlieren mirror. When the schlieren mirror images showed that the breathing air escapes beyond the $100 \mathrm{~cm}$ diameter range of the mirror, an evaluation of the BOS method is presented in rectangular figures. Thus, the following sections show the maximal range of the escaping breathing air for each musical instrument or singer.

Furthermore, it should be taken into consideration that each musician has developed their blowing technique, which also differs due to their physical characteristics. To control the breathing 

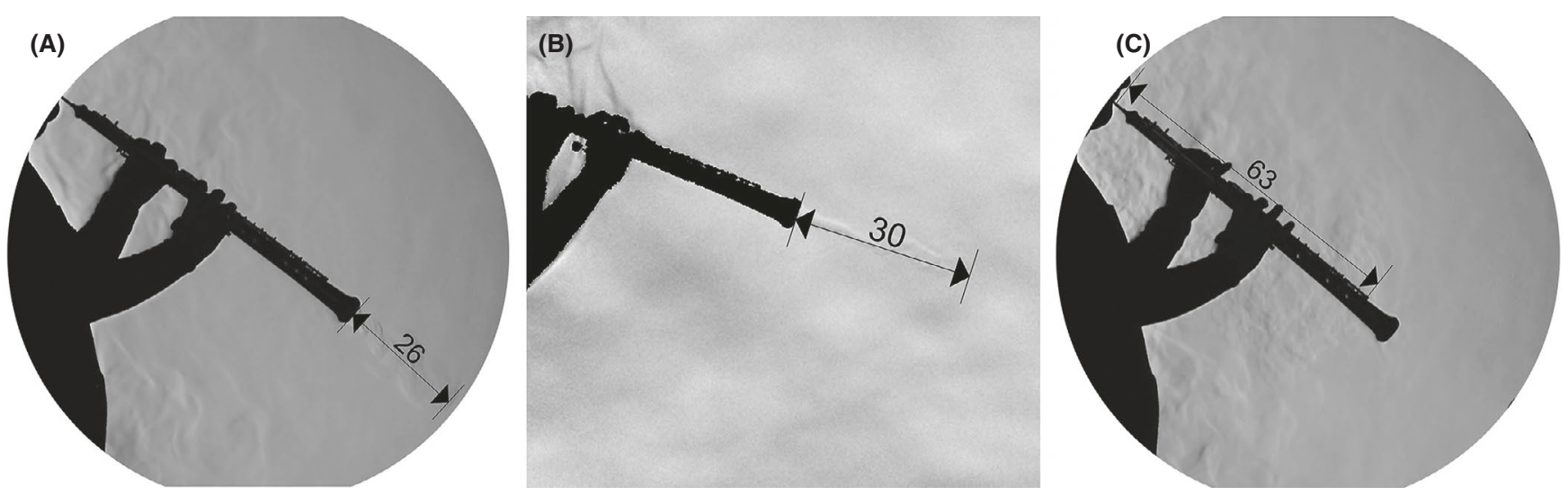

FIGURE 5 Maximal range of the air escaping from the bell of the oboe while playing the note $\mathrm{Bb} 3 \approx 233 \mathrm{~Hz}(\mathrm{~A})$, note $\mathrm{D} 6 \approx 1175 \mathrm{~Hz}(\mathrm{~B})$, and when intermittently exhaling $(C)(\mathrm{cm})$

when playing a wind instrument or singing, several parameters have to be taken into account to accomplish stable breath support and, therefore, a clear sound. The expelled air and the involved organs (throat, larynx and vocal cords, and lungs and diaphragm) form a flexible system. The different wind instruments require specific demands on the blowing techniques. When playing flute instruments, the respiratory pressure is even and relatively low. The breathing muscles mostly counteract the passive exhalation forces of the rib cage, which causes the diaphragm to tense during exhalation. When playing brass instruments like the trumpet or the horn, a much higher respiratory pressure is needed to overcome the resistance of the mouth lips and the instrument, whereby the abdominal wall muscles are more important. Additionally, the individual physique of the musician plays a major role in the function and process of respiration. ${ }^{28}$ The angle at which the instrument is held also has to be taken into account to properly estimate the direction in which the air escapes from the mouth, bell, or tone holes as well as when exhaling intermittently between phrases (e.g., oboe, bassoon) or leaking air near the mouthpiece (e.g., clarinet, bass clarinet). Additionally, the movement of the musicians and their instruments have to be taken into consideration. These movements, which naturally occur when playing musical pieces will also move the surrounding air and increase the distribution (not the maximum range) of the escaping breathing air. Furthermore, due to these movements, it is possible that the sensors did not capture the core of the jet ejected from the bell where the highest velocity occurs, which could lead to falsified results.

Thus, the results presented in this study should not be generalized to all players of wind instruments or singers and their musical performances.

\subsection{Woodwind instruments}

In the case of woodwind instruments, in addition to the breathing air escaping from the bell, the air exiting from the tone holes and the air blown over the mouthpiece in the case of flutes have to be considered. The intermittent exhalation in the case of the oboe and the bassoon, as well as the air leaking near the mouthpiece in the case of the clarinet and the bass clarinet also have to be taken into account. When looking at the foot joints of the instruments, it can be observed that, especially for small bores, the air escapes relatively laminarly from the bell. After a certain distance, the airflow becomes turbulent and finally mixes with the surrounding room air. How far the air escapes into the room varies concerning the instrument.

\subsection{1 | Oboe}

The tone holes of the oboe are covered with keys that have small holes from which a small amount of air can escape. However, this airflow is hard to capture in the images due to its small range and the small density gradient. Most of the air blown into the instrument escapes from the bell and moves up to $26 \mathrm{~cm}$ into the room when playing the note $\mathrm{Bb} 3 \approx 233 \mathrm{~Hz}$ (Figure $5 \mathrm{~A}$ ) and up to $30 \mathrm{~cm}$ when playing the note $\mathrm{D} 6 \approx 1175 \mathrm{~Hz}$ (Figure $5 \mathrm{~B}$ ). Due to the small double reed, in which the air is blown into the instrument, the oboe is played with little breathing air but with high respiratory pressure. Therefore, the breathing air cannot escape completely from the tone holes and the bell and the oboe player has to exhale intermittently through the mouth and nose between phrases. Here, the air spreads approximately $60 \mathrm{~cm}$ into the room (Figure $5 \mathrm{C}$ ) but does not exceed the length of the oboe.

The anemometry measurements show that the velocity of the breathing air is the highest when playing at high pitches (up to $v_{\text {average }} \approx 0.09 \mathrm{~m} / \mathrm{s}$, Figure 6 ). This confirms the results shown in Figure $5 \mathrm{~B}$, where the air spreads the farthest when playing the note D6. High velocities can also be found during intermittent exhalation, followed by a continuous decrease (Figure 6). Here, the small velocities near the farthest sensor may occur due to the surrounding room air moving since the air spreads only approximately $60 \mathrm{~cm}$ when exhaling intermittently (Figure 5C). When playing at low pitches or playing longer phrases, the velocity of the breathing air escaping from the bell is much lower and, again, decreases with increasing distance. 
However, when playing a musical piece, the flow is notably transient (Figure 7). Air movement of $v \approx 0.02 \mathrm{~m} / \mathrm{s}$ at $85 \mathrm{~cm}$ from the bell still can be observed. This does not necessarily indicate air movement from the flow escaping from the bell; it might be explained by the convective flow of the surrounding room air. The velocity measured by the nearest sensor (at $20 \mathrm{~cm}$ from the bell) peaks at $t \approx 45 \mathrm{~s}$. This corresponds to the large emission of breathing air shown in Figure 5A,B. These jets are highly transient and escape the bell irregularly.

\subsection{2 | Bassoon}

When playing the bassoon at lower pitches where most of the tone holes are covered, nearly all the air blown into the instrument escapes from the bell (Figure 8A). At high pitches, where many tone holes are open, hardly any air escapes from the bell. Here, a smaller jet can be observed near the tone holes. The largest airflow escaping from the tone holes occurs when playing the note $F 3 \approx 175 \mathrm{~Hz}$, where most of the tone holes are not covered (Figure 8B). Similar to the oboe, the bassoon is played with high respiratory pressure. Due to the small double reed, in which the air is blown into the instrument, the air cannot escape completely from the bell and the tone holes. Thus, it needs to be exhaled intermittently and spreads approximately $50 \mathrm{~cm}$ into the room (Figure $8 \mathrm{C}$ ).

Investigations with the BOS method showed that the airflow escaping from the bell does not move any farther than what the schlieren images illustrated (Figure 8A) and, thus, confirm the measurements with the schlieren imaging method.

The anemometry measurements show that the highest velocity of the air escaping from the bell up to approximately $0.13 \mathrm{~m} / \mathrm{s}$ occurs when playing the note $\mathrm{Bb} 1$, where nearly all the air escapes from the bell (Figure 9). When playing at high pitches, nearly no velocity of the air escaping from the bell could be measured. The velocity of the air escaping from the tone holes when playing the note F3 increases slightly but continuously with increasing distance. Once again, intermittent exhalation features the highest air velocities similar to the oboe.

\subsection{3 | Bb clarinet and bass clarinet}

The breathing air, which is blown into the instrument, can escape completely from the bell and the tone holes and reaches up to approximately $25 \mathrm{~cm}$ from the bell into the room when playing at low pitches (Figure 10A) and slightly more when playing at high pitches (Figure 10B). At the tone holes, which are covered with keys that have small holes, almost no moving air can be observed due to its small range and small density gradients. In addition to the air escaping from the bell, the breathing air leaking at the mouthpiece has to be considered. This occurs when the lips of the clarinet player tire during long rehearsals or concerts. Leaking air can also be observed when playing a tone with an accent (staccato) or with untrained musicians playing the clarinet, such as beginners or older clarinet players. Here, the clarinet player simulated her lips tiring, which results in the air leaking near the mouthpiece (Figure 10C).

Investigations with the BOS method showed that the airflow leaking at the mouthpiece does not move any farther than what the schlieren images illustrated and, therefore, confirm the measurements with the schlieren imaging method.

The anemometry measurements show that the highest velocity of the air escaping from the bell occurs when playing at low pitches opposite to the visualization in Figure 10A,B. The air leaking at the mouthpiece has a slightly higher velocity up to approximately $0.15 \mathrm{~m} / \mathrm{s}$, which decreases rapidly until it is almost immeasurable at the farthest sensor (Figure 11).

The air escaping from the bell of the bass clarinet is transported nearly vertically into the room when the instrument is aligned vertically. Similar to the Bb clarinet, almost no jet of air can be seen at the tone holes. When playing at lower pitches where most of the tone holes are covered, most of the air escapes from the bell of the instrument (Figure 12A). When playing a musical piece, the air reaches the farthest into the room with a distance of up to $33 \mathrm{~cm}$ (Figure 12C).

\subsubsection{Grand flute, piccolo, and alto flute}

The air escaping from the foot joint of the grand flute and the piccolo is similar. When playing these instruments, a similarly large jet of air escapes from the end of the flutes with a range of approximately $20 \mathrm{~cm}$ (Figure 13A,B). Regarding the alto flute, the air escapes much farther into the room compared to the smaller flutes (Figure 13C). Near the tone holes of the instruments, which are covered with keys, hardly any escaping air can be observed.

Within the range of each instrument, the air being expelled through the foot joint escapes the farthest when playing at low pitches, where most of the tone holes are covered (Figure 13).
FIGURE 6 Average velocity of the air escaping from the bell of the oboe (note D6, Bb3, musical piece) and when intermittently exhaling

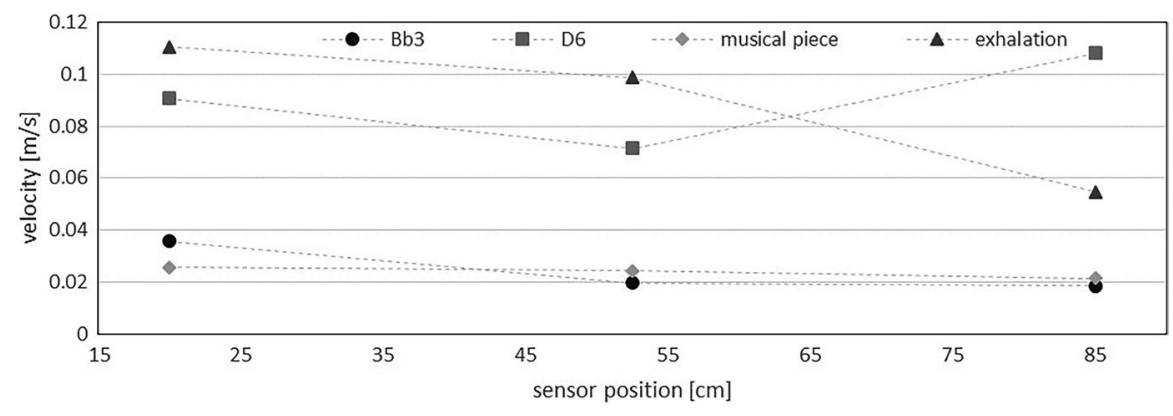




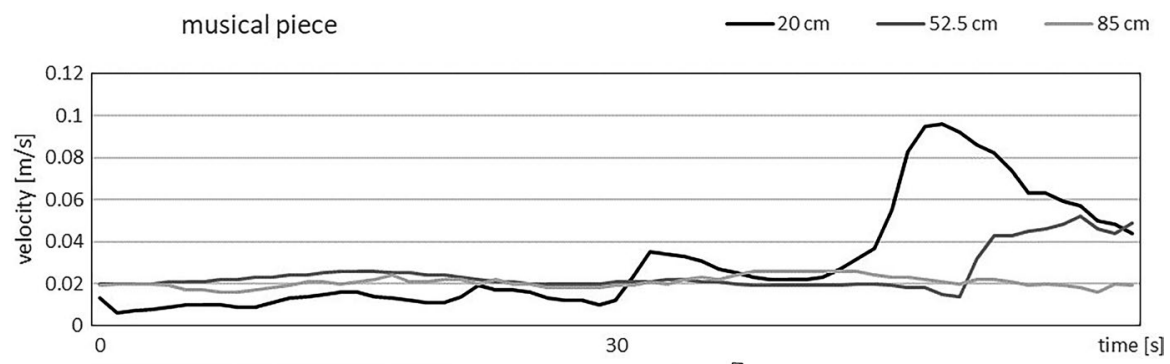

FIGURE 7 Velocity of the air escaping from the bell of the oboe when playing Bohuslav Martinů: Concerto for Oboe and Small Orchestra
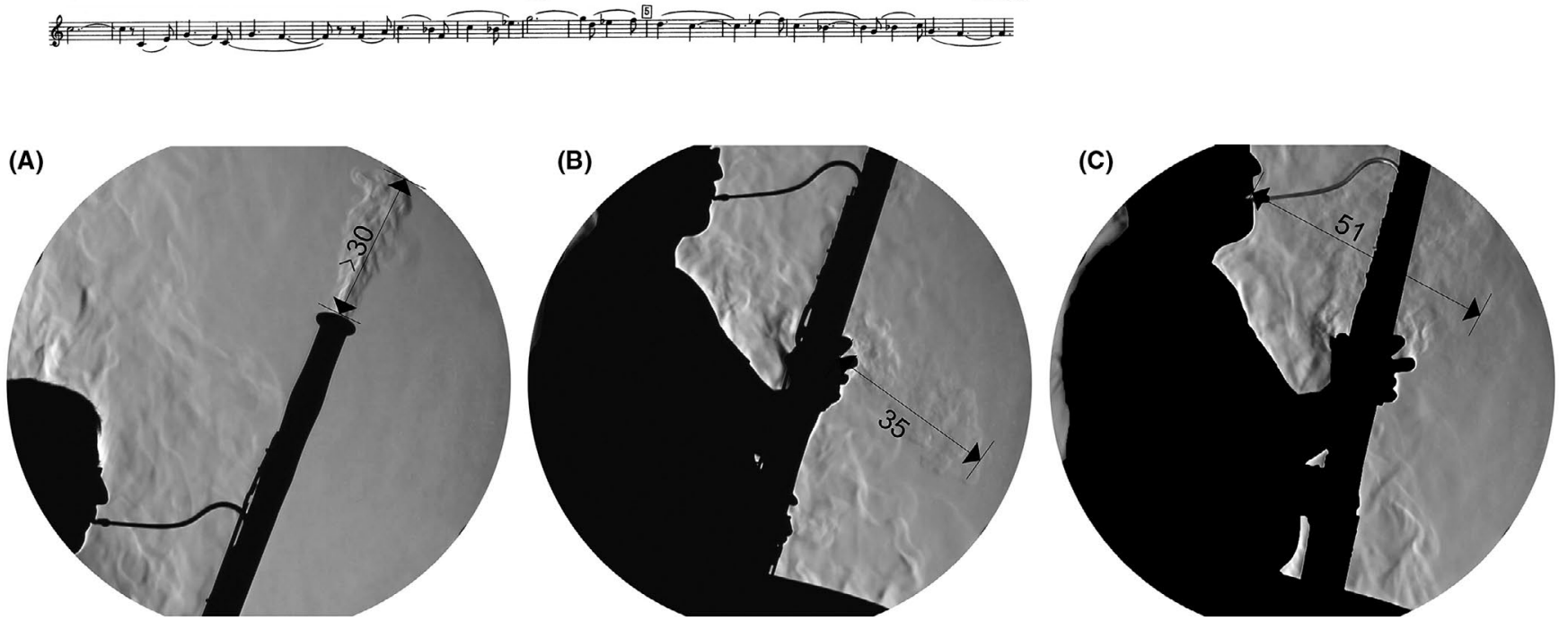

FIGURE 8 Maximal range of the air escaping from the bell or the tone holes of the bassoon while playing the note $\mathrm{Bb} 1 \approx 58 \mathrm{~Hz}(\mathrm{~A})$, note $\mathrm{F} 3 \approx 175 \mathrm{~Hz}(\mathrm{~B})$, and when intermittently exhaling $(\mathrm{C})(\mathrm{cm})$

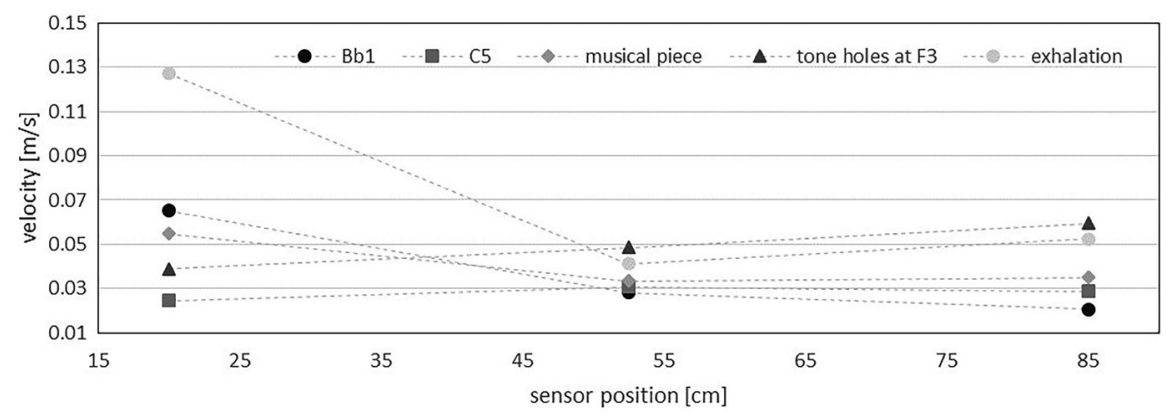

FIGURE 9 Average velocity of the air escaping from the bell of the bassoon (single note Bb1, C5, musical piece), from the tone holes (F3) and when intermittently exhaling
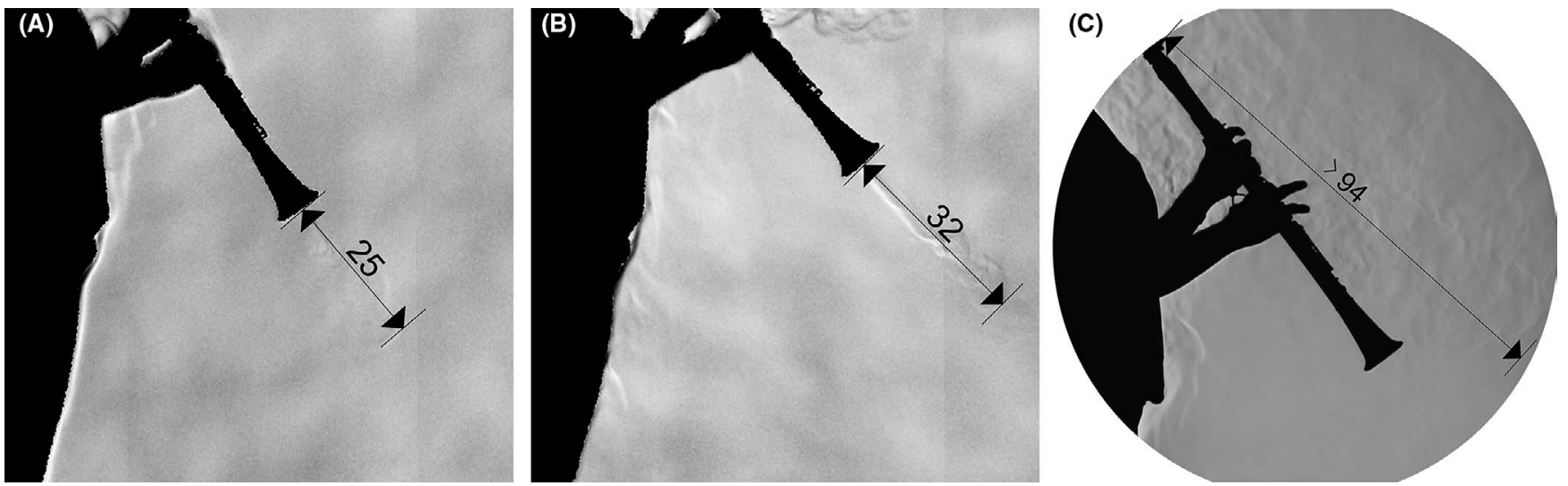

FIGURE 10 Maximal range of the air escaping from the bell of the Bb clarinet while playing the note $\mathrm{C \# 3} \approx 139 \mathrm{~Hz}(\mathrm{~A})$, note $\mathrm{E} 6 \approx 1319 \mathrm{~Hz}$ $(B)$, and the air leaking at the mouthpiece (C) $(\mathrm{cm})$ 
FIGURE 11 Average velocity of the air escaping from the bell of the Bb clarinet (single note C\#3, E6, musical piece) and near the mouthpiece (leaking air, staccato)
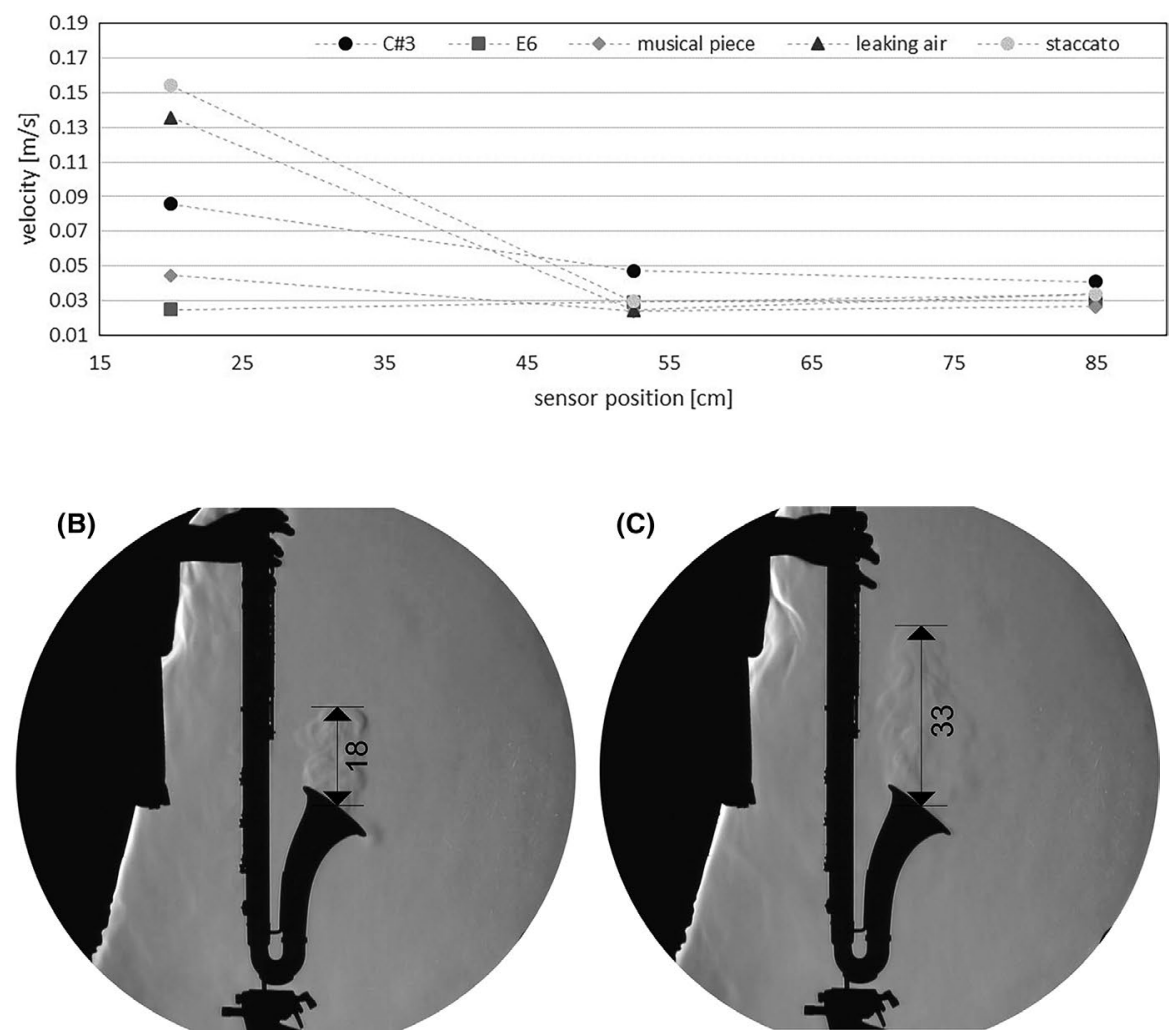

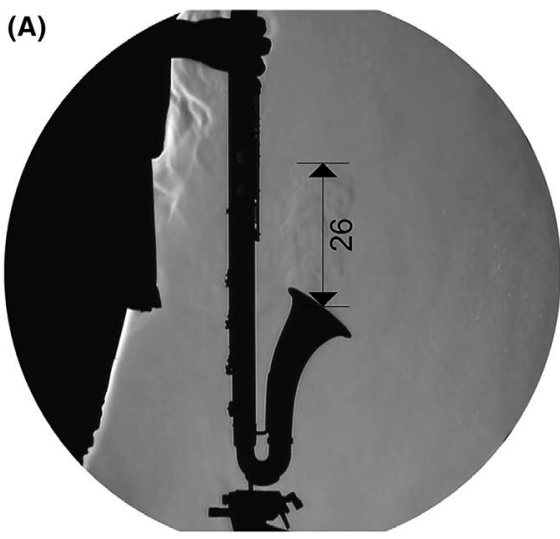

FIGURE 12 Bass clarinet while playing the note $D 2 \approx 73 \mathrm{~Hz}(\mathrm{~A})$, note $\mathrm{Bb} 4 \approx 466 \mathrm{~Hz}(\mathrm{~B})$, and the maximal range of the air escaping from the bell $(\mathrm{C})(\mathrm{cm})$
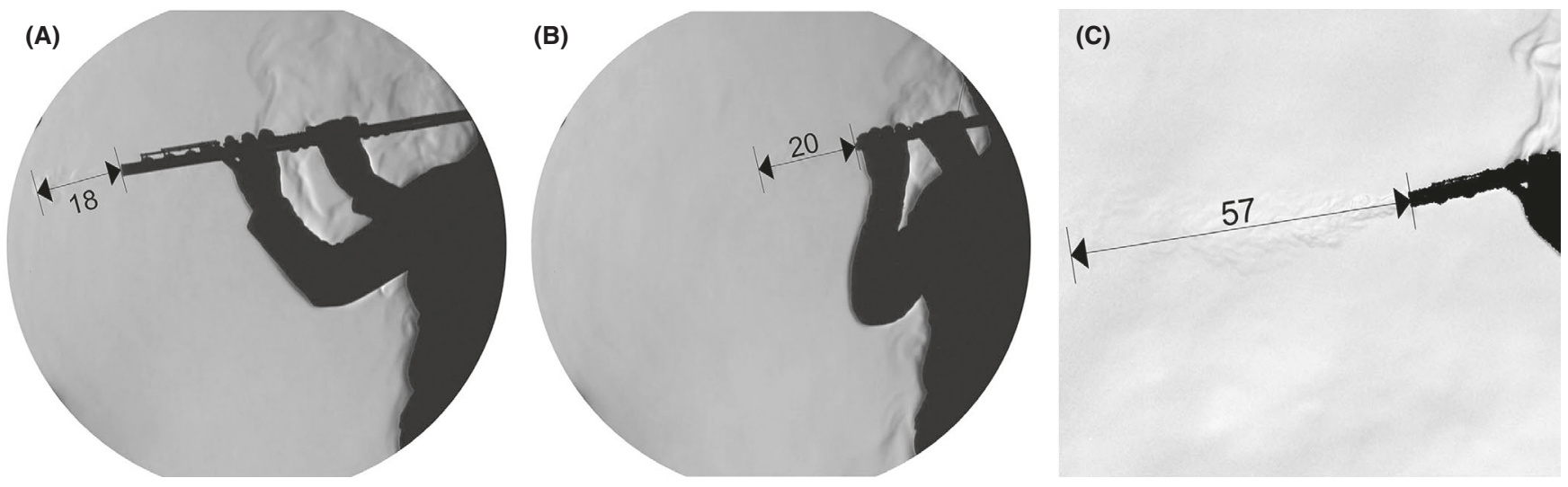

FIGURE 13 Maximal range of the air escaping from the foot joint of the grand flute while playing the note $\mathrm{E} 4 \approx 330 \mathrm{~Hz}$ (A), of the piccolo while playing the note $\mathrm{E} 5 \approx 659 \mathrm{~Hz}(\mathrm{~B})$, and of the alto flute when playing the note $\mathrm{G} 2 \approx 98 \mathrm{~Hz}(\mathrm{C})(\mathrm{cm})$

Figure 14 shows that the velocity of the air escaping from the foot joint when playing the alto flute at low pitches is the highest (up to approximately $0.1 \mathrm{~m} / \mathrm{s}$ ) compared to the smaller flutes playing at higher pitches (approximately $0.05 \mathrm{~m} / \mathrm{s}$ for the grand flute and $0.03 \mathrm{~m} / \mathrm{s}$ for the piccolo). This also confirms the BOS image of the alto flute in Figure 13C, where the air escapes the farthest from the foot joint of the alto flute.

However, most of the breathing air is blown over the mouthpiece of the flutes. The air is cut at the splitting edge and moves either into the bore of the instrument or into the room over the mouthpiece.
Here, the air escapes the farthest into the room (Figure 15) compared to the air escaping from the foot joints (Figure 13).

When playing notes in forte, more air is blown at a higher velocity over the mouthpiece of the instrument. To keep the pitch stable, the angle at which the air is blown into the instrument is varied. ${ }^{28}$ The evaluations show that the higher the instrument and therefore the tone played, the more air is blown over the mouthpiece in a vertical direction (Figure 15B). Regarding the alto flute, which can be played at the lowest pitches in comparison to the grand flute and piccolo, the air is blown nearly horizontally into the room 

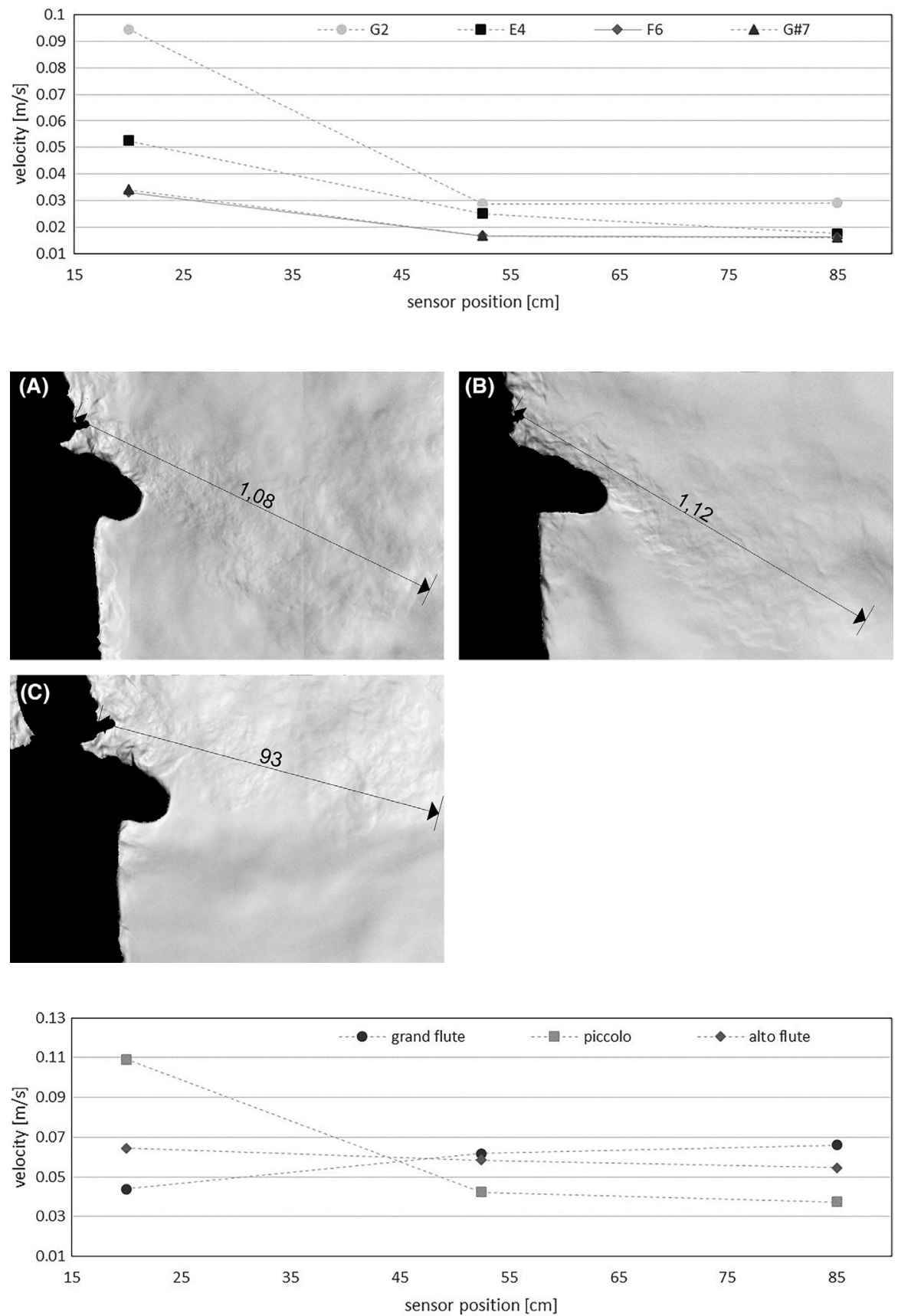

FIGURE 14 Average velocity of the air escaping from the foot joint (single note G2 (alto), E4 and F6 (grand flute), and G\#7 (piccolo))

FIGURE 15 Maximal range of the air blown over the mouthpiece of the grand flute $(A)$, the piccolo $(B)$, and the alto flute $(C)$ when playing a musical piece at medium pitches $(\mathrm{cm})$
(Figure 15C). Additionally, the air blown over the mouthpiece moves farther when playing the piccolo at high pitches (up to approximately $0.11 \mathrm{~m} / \mathrm{s}$ ) compared to playing the grand and alto flute at lower pitches (Figure 16). Furthermore, the velocity of the air blown over the mouthpiece increases when playing at high pitches, which confirms the visualizations in Figure 15.

\section{2 | Brass instruments}

The breathing air blown into the mouthpiece of the brass instruments can escape completely from the bell. Usually, no air leaks near the mouthpiece. Leaking air can only be observed with beginners, who are not assessed in this study. The various natural tones of a brass instrument are played by varying the pressure of the lips and the breathing air. This affects the range and angles at which the air escapes from the bell. If non-natural tones are played, valves (e.g., $\mathrm{Bb}$ trumpet, French horn, $\mathrm{F}$ tuba) or slides (e.g., tenor trombone) are used to lengthen or shorten the air column inside the instrument to be able to play at every possible pitch and scale.

In contrast to the woodwind instruments, the air escaping from the bells of the brass instruments is highly turbulent. This is due to the larger diameter of the bells compared to the foot joints of the woodwind instruments. Moreover, mutes and dampers are used commonly with brass instruments. When playing with mutes or dampers, the air escapes through the narrow gap between the brass of the instrument and the material of the damper. This alters the spread of the air escaping from the bell significantly. Further details 
about the impact of dampers are presented and discussed for each instrument in the following sections.

\subsection{1 | Bb trumpet}

The pitch of the played note affects how far and at which angle the air escapes from the bell (Figure 17A,B). When playing at high pitches, the air escapes at a higher velocity and higher pressure from the mouth of the trumpet player. However, when playing at high pitches and high volume, no larger volume of air is required. ${ }^{28}$ If dampers are used, the airflow escaping from the bell is restricted significantly (Figure 17C).

When playing at lower pitches or playing a musical piece, only a low velocity of the escaping airflow can be measured at a distance of $20 \mathrm{~cm}$ in front of the bell (Figure 18). When playing at low pitches, the air escapes at a higher velocity up to approximately $0.07 \mathrm{~m} / \mathrm{s}$. When examining the values measured by the sensor that is the farthest from the bell at $85 \mathrm{~cm}$, the measurements show little air movement mainly resulting from the movement of the surrounding indoor air.

\subsection{2 | Tenor trombone}

The pitch of the note played affects how far and at which angle the air escapes from the bell (Figure 19A,B). If dampers are used, the airflow escaping from the bell is restricted significantly (Figure 19C). Unlike other brass instruments, the notes that vary from the natural tone scale of the instrument are produced by moving the slide of the trombone, thereby lengthening or shortening the air column inside the bore of the instrument. Hence, the air escaping from the bell is swirled when playing non-natural tones.

Figure 20 shows that the velocity of the escaping breathing air is generally low with the highest value when playing at high pitches (up to approximately $0.05 \mathrm{~m} / \mathrm{s}$ ). For playing at lower pitches and a musical piece, the velocity decreases with increasing distance (the final increase is the result of surrounding convective flows). When playing the note $\mathrm{Bb} 1$, the velocity of the escaping breathing air decreases constantly. However, compared to the other brass instruments, the velocity of the breathing air escaping from the bell is rather low.

\subsubsection{French horn}

The French horn is usually held with the right hand; the valves are controlled with the left hand. When playing at higher pitches, the air escapes farther into the room compared to playing at lower pitches. The escaping breathing air reaches the farthest when playing a musical piece (Figure 21A). If dampers are used, the jet of air escaping from the bell is reduced and bent along the right hand or forearm (Figure 21B). An exception is the stopping mute, where the air escapes from a narrow tube at a higher
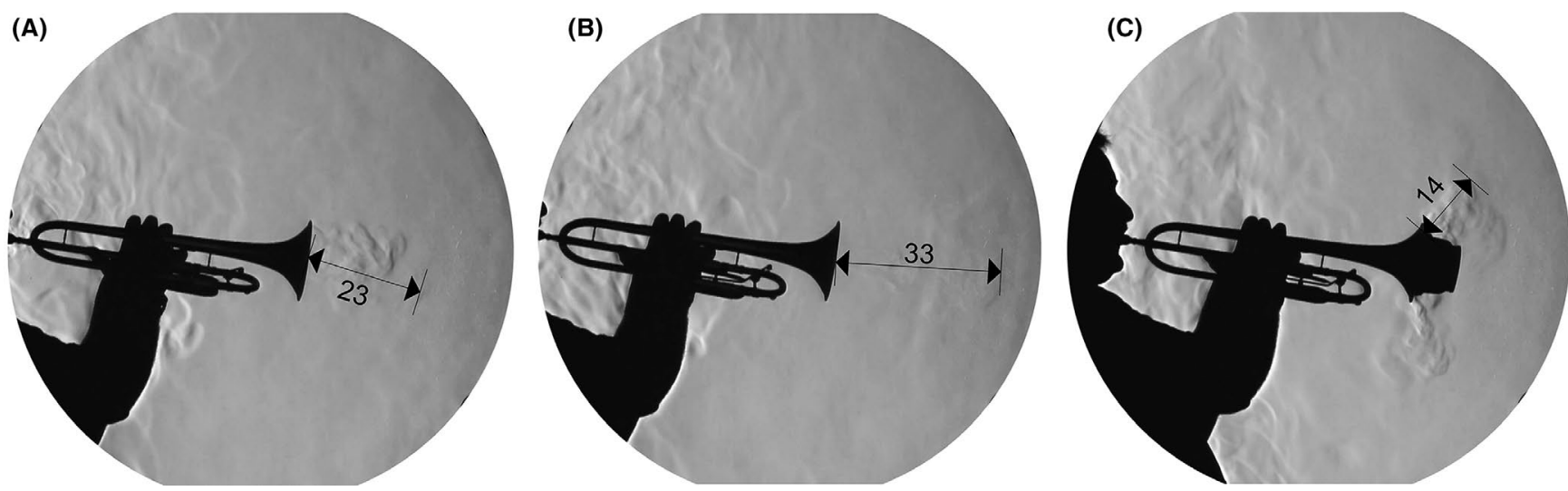

FIGURE 17 Maximal range of the air escaping from the bell of the $\mathrm{Bb}$ trumpet while playing the note $\mathrm{Bb} 3 \approx 233 \mathrm{~Hz}(\mathrm{~A})$, note $\mathrm{Bb} 5 \approx 932 \mathrm{~Hz}(\mathrm{~B})$, and with cup mute (fully closed) (C) (cm)

FIGURE 18 Average velocity of the air escaping from the bell of the $\mathrm{Bb}$ trumpet (single note $\mathrm{Bb} 3, \mathrm{Bb} 6$, musical piece)

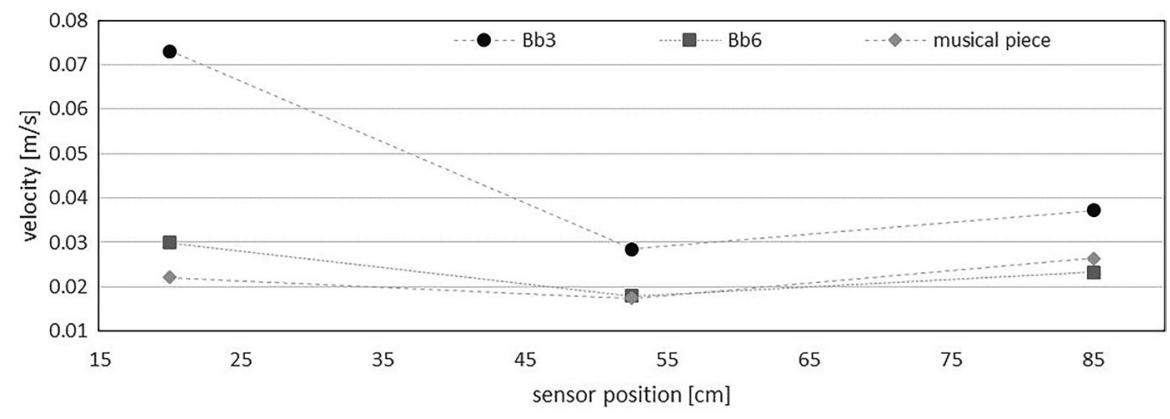



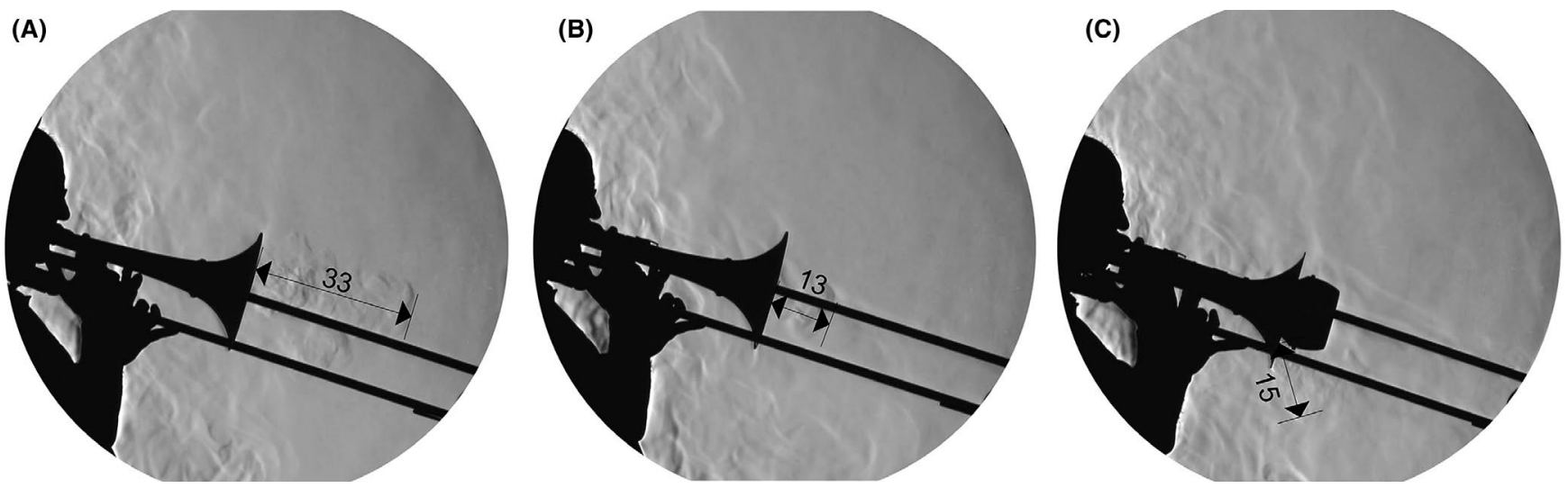

FIGURE 19 Maximal range of the air escaping from the bell of the tenor trombone while playing the note $\mathrm{Bb} 1 \approx 58 \mathrm{~Hz}(\mathrm{~A})$, note $\mathrm{Bb} 3 \approx 233 \mathrm{~Hz}(\mathrm{~B})$, and with damper (C) $(\mathrm{cm})$

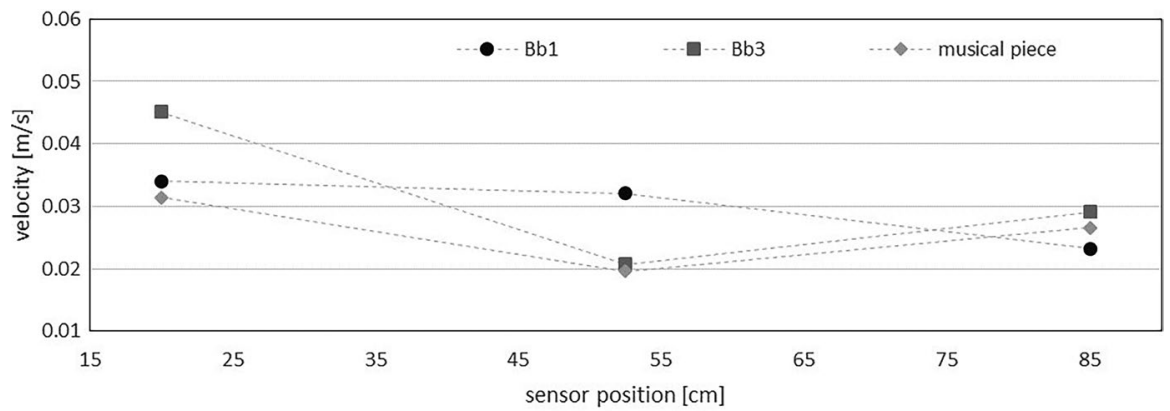

FIGURE 20 Average velocity of the air escaping from the bell of the tenor trombone (single note $\mathrm{Bb} 1, \mathrm{Bb} 3$, musical piece)
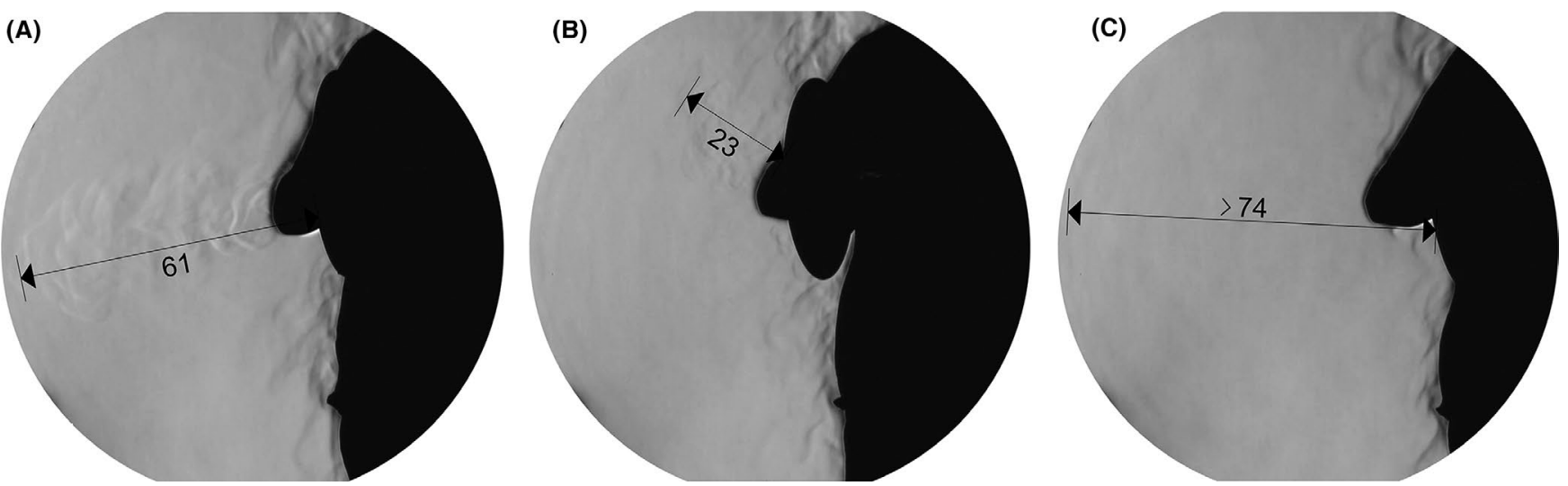

FIGURE 21 Maximal range of the air escaping from the bell of the French horn while playing a musical piece (A), with damper (B), and stopping mute $(\mathrm{C})(\mathrm{cm})$

velocity. Thus, the air spreads farther than $70 \mathrm{~cm}$ into the room and escapes over the edge of the schlieren mirror. However, the flow is more difficult to detect due to the lower density gradient (Figure 21C).

Investigations with the BOS method showed that the air escaping from the bell with stopping mute does not move any farther than what the schlieren images illustrated and, therefore, confirm the measurements with the schlieren imaging method.

Figure 22 shows that the velocity of the escaping breathing air is $v<0.03 \mathrm{~m} / \mathrm{s}$. As the measured values are similar to the background air velocity during the measurements without any instruments, they are negligible.

\subsubsection{F tuba}

Figure 23A,B show that the air escaping from the bell is transported into the room only over a short distance. In contrast to the other brass instruments, the air escapes farther when dampers are used (Figure 23C).

The anemometry measurements show that the breathing air escapes at higher velocity from the bell when playing at high pitches (Figure 24). As the airflow only reaches approximately $15 \mathrm{~cm}$ into the room, the velocity measured with the farthest sensor only shows random disturbances, which could occur due to the breathing air escaping from the bell building small eddies. When playing at lower 
FIGURE 22 Average velocity of the air escaping from the bell of the French horn (single note C2, D\#5, musical piece)
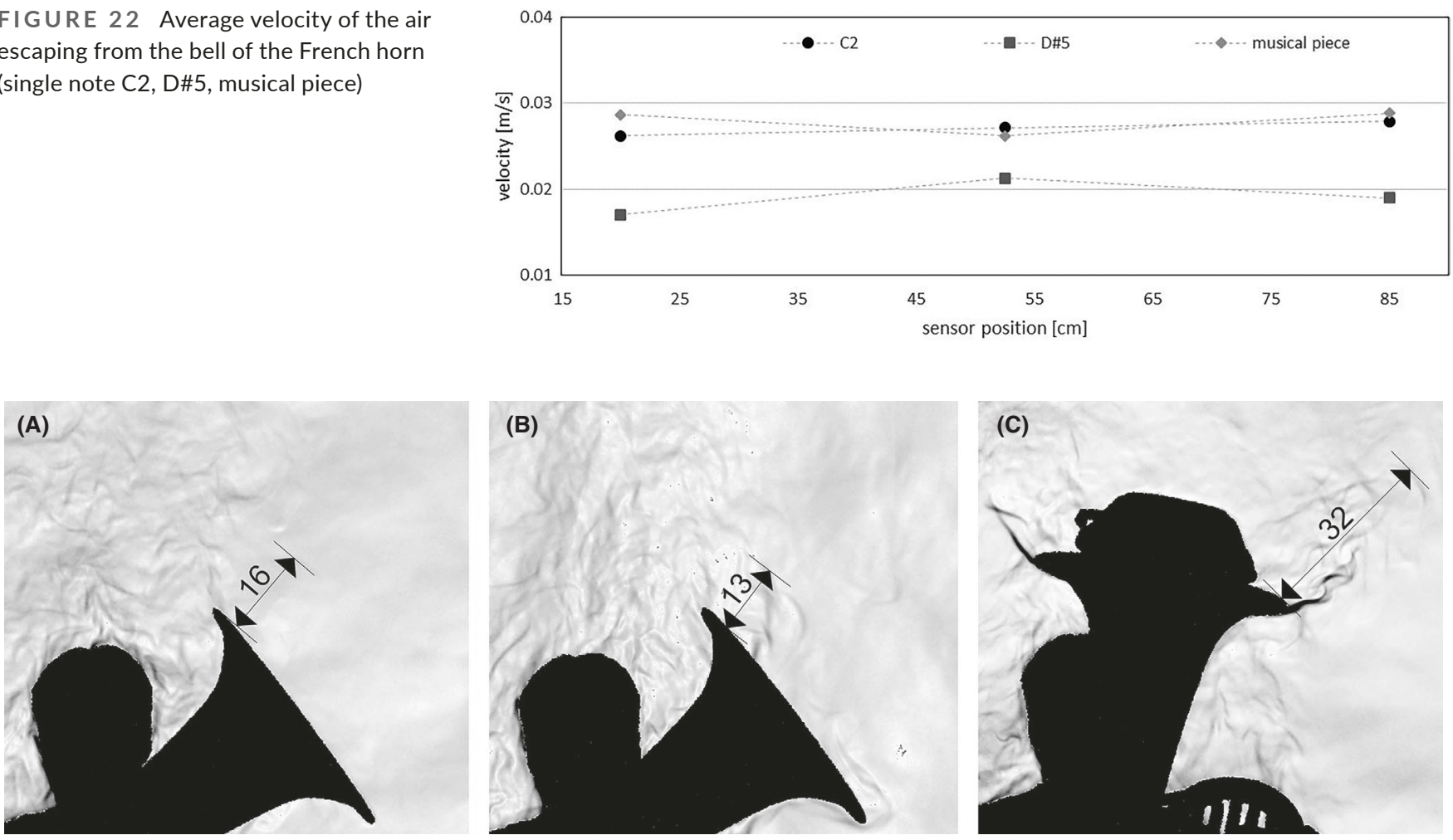

(B)

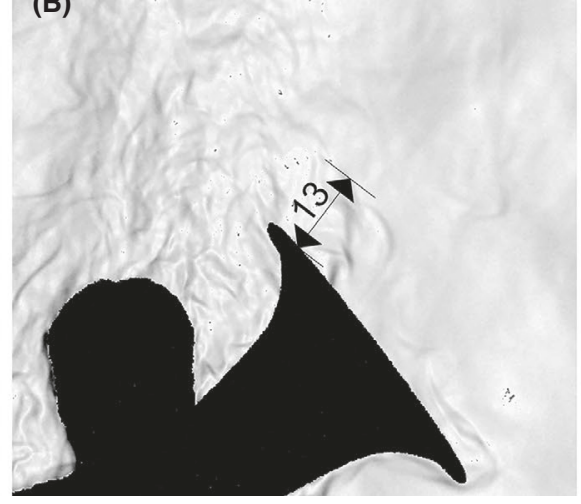

(C)

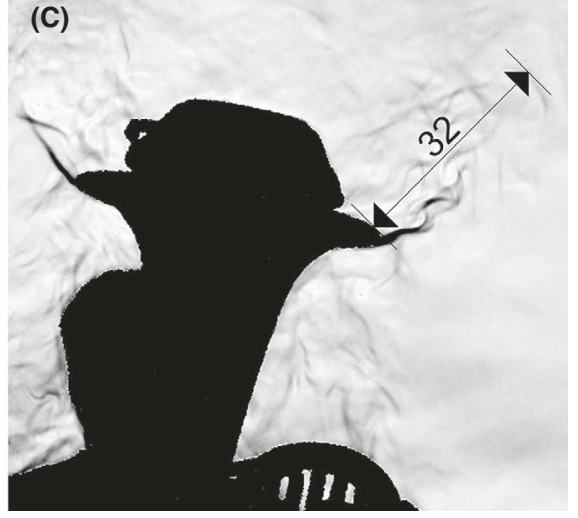

FIGURE 23 Maximal range of the air escaping from the bell of the $\mathrm{F}$ tuba while playing the note $\mathrm{F} 1 \approx 44 \mathrm{~Hz}(\mathrm{~A})$, note $\mathrm{F} 4 \approx 349 \mathrm{~Hz}(\mathrm{~B})$, and with damper $(\mathrm{C})(\mathrm{cm})$

FIGURE 24 Average velocity of the air escaping from the bell of the $F$ tuba (single note F1, F4, musical piece)

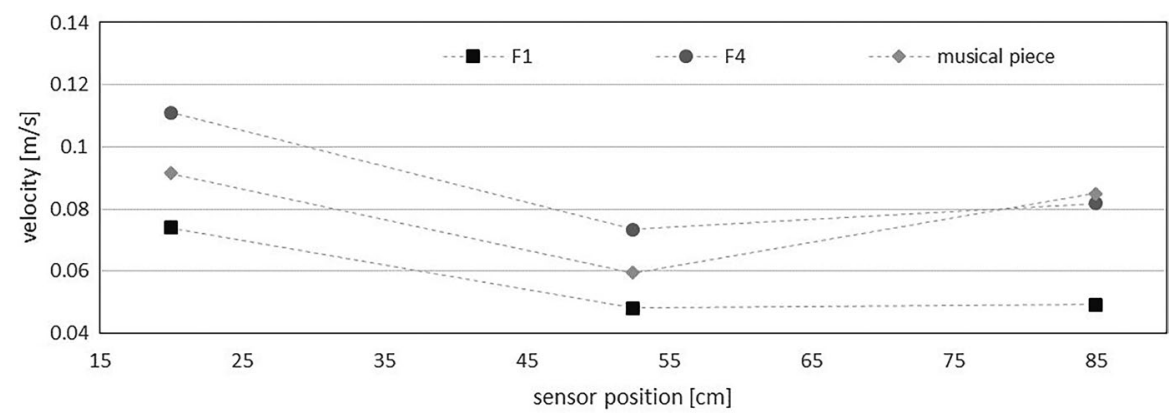

pitches, the air escapes at a low velocity and reaches a constant velocity near the middle sensor at $52.5 \mathrm{~cm}$.

\section{3 | Singers}

When singing a note, the greatest air spread can be observed at the beginning of the tone production. If a tone is held or a longer phrase is sung, only a small amount of air escapes from the mouth of the singer. In contrast, the greatest air spread can be seen when singing consonants and with high activities during articulation.

\subsection{1 | Baritone}

The evaluations show that the range of the expelled air hardly differs in the variation of the pitch (e.g., when singing scales) (Figure 25A,B). An increasing air spread can be observed when singing demanding musical pieces that include consonants and require high levels of articulation as well as a strong command of the voice (Figure 25C).

The anemometry measurements show that the velocity of the escaping breathing air is the highest when singing at low pitches or a demanding musical piece with a velocity up to approximately $v \approx 0.13 \mathrm{~m} / \mathrm{s}$ (Figure 26 ). The velocity measured when singing a musical piece was still detectable by the farthest sensor at $85 \mathrm{~cm}$ from the mouth. This can also be seen in Figure $25 \mathrm{C}$ where the air spreads farther than $90 \mathrm{~cm}$ into the room. When singing single notes at either low or high pitches, the velocity cannot be detected near the middle sensor, which corresponds to the visualizations shown in Figure 25A,B.

\subsection{2 | Soprano}

Similar to the baritone, the evaluations show that the range of the expelled air hardly differs in the variation of the pitch (e.g., when singing scales) (Figure 27A,B). Again, an increasing air spread can be 

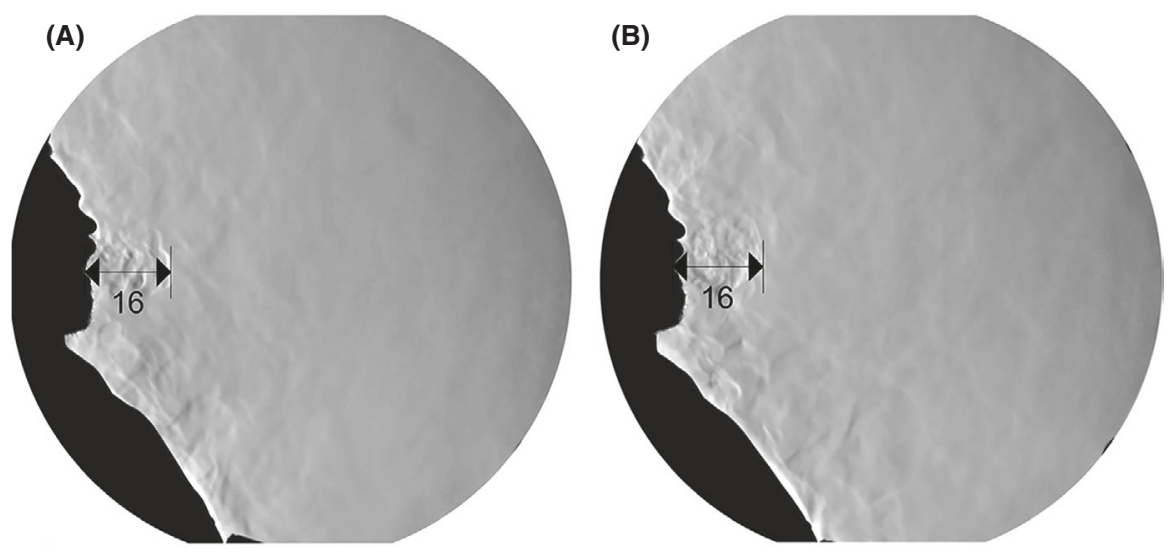

FIGURE 25 Maximal range of the air escaping from the mouth while singing the note $\mathrm{G} 2 \approx 98 \mathrm{~Hz}(\mathrm{~A})$, note $\mathrm{D} \# 5 \approx 622 \mathrm{~Hz}$ $(\mathrm{B})$, and a demanding musical piece $(\mathrm{C})(\mathrm{cm})$
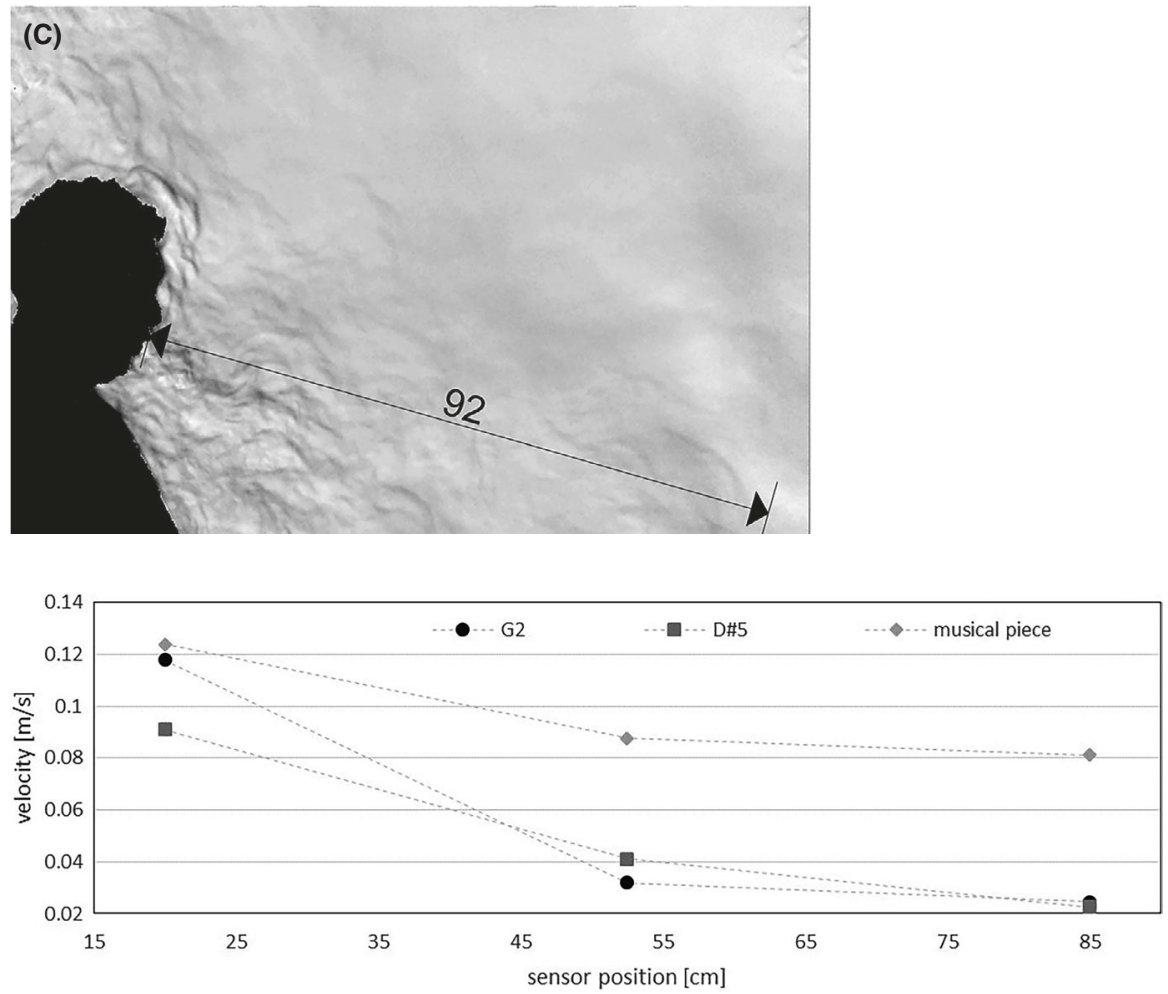

FIGURE 26 Average velocity of the air escaping from the mouth of the baritone (single note G2, D\#5, musical piece)

observed when singing demanding musical pieces that include consonants and require high levels of articulation as well as a strong command of the voice (Figure 27C).

Similar to the velocity measurements of the baritone, the velocity of the escaping breathing air from the soprano is the highest when singing a demanding musical piece (up to approximately $v \approx 0.14 \mathrm{~m} / \mathrm{s}$ ). However, in contrast to the baritone singer, a lower air velocity can be observed for the soprano when singing at low pitches. Near the middle sensor hardly any air movement can be observed, which corresponds to both singing a single note or a musical piece (Figure 28).

Figure 29 shows the transient behavior of the air velocity recorded during the singing of an aria. It illustrates that only the nearest sensor (at $20 \mathrm{~cm}$ from the mouth) measures values of up to $v \approx 0.2 \mathrm{~m} / \mathrm{s}$. The sensors that are farther away from the singer only show small velocity values of maximal $v \approx 0.08 \mathrm{~m} / \mathrm{s}$. However, the velocity measured at the middle sensor (at $52.5 \mathrm{~cm}$ ) is shifted slightly in terms of chronology compared to the first sensor at $20 \mathrm{~cm}$. This applies to the airflow measured by the first sensors and captured by the second sensor a few seconds later when moving at these low velocities.

\section{DISCUSSION AND OUTLOOK}

Especially during the ongoing COVID-19 pandemic, there is a great demand for information about the risk of cross-infection when playing wind instruments and singing. The findings presented in this study help to estimate proper distances between the musicians during rehearsals or performances to ensure a safe environment during the pandemic. Additionally, the information presented help to obtain a holistic understanding of the spreading range and behavior of the escaping breathing air. Using this information, it is possible to develop efficacious safety precautions for both musicians and the audience as well as to position the musicians in orchestras and other musical arrangements to ensure a safe environment. 


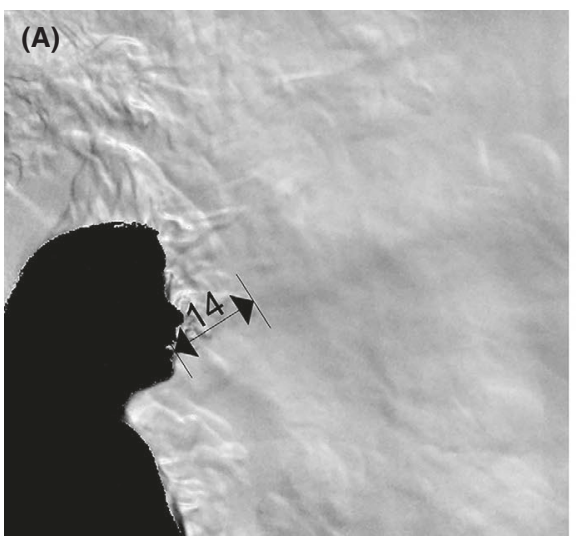

FIGURE 27 Maximal range of the air escaping from the mouth while singing the note $A 3 \approx 220 \mathrm{~Hz}(\mathrm{~A})$, note $\mathrm{A} 5 \approx 880 \mathrm{~Hz}(\mathrm{~B})$, and a demanding musical piece (C) $(\mathrm{cm})$

FIGURE 28 Average velocity of the air escaping from the mouth of the soprano (single note $\mathrm{A} 3, \mathrm{~A} 5$, musical piece)
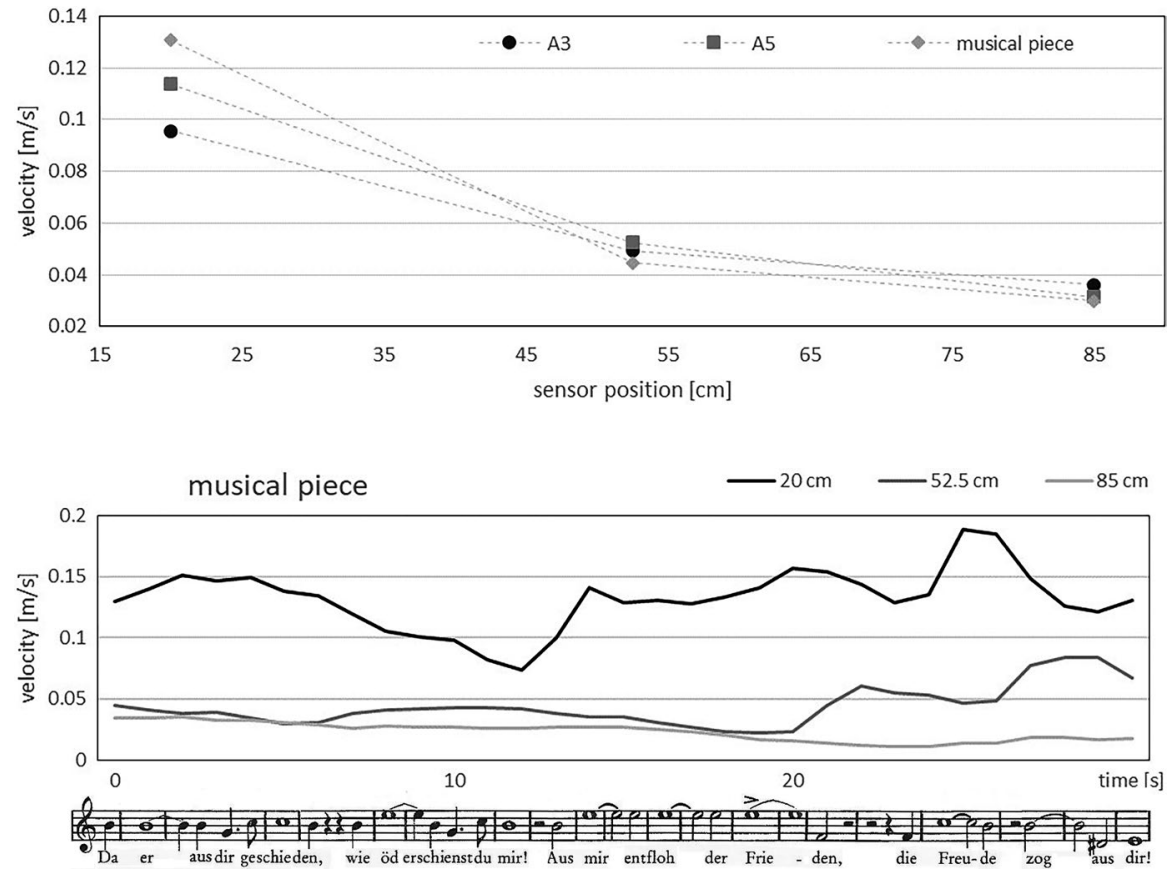

FIGURE 29 Velocity of the air escaping from the mouth of the soprano singer when singing Richard Wagner: Dich, teure Halle, grüß' ich wieder. Tannhäuser und der Sängerkrieg auf der Wartburg
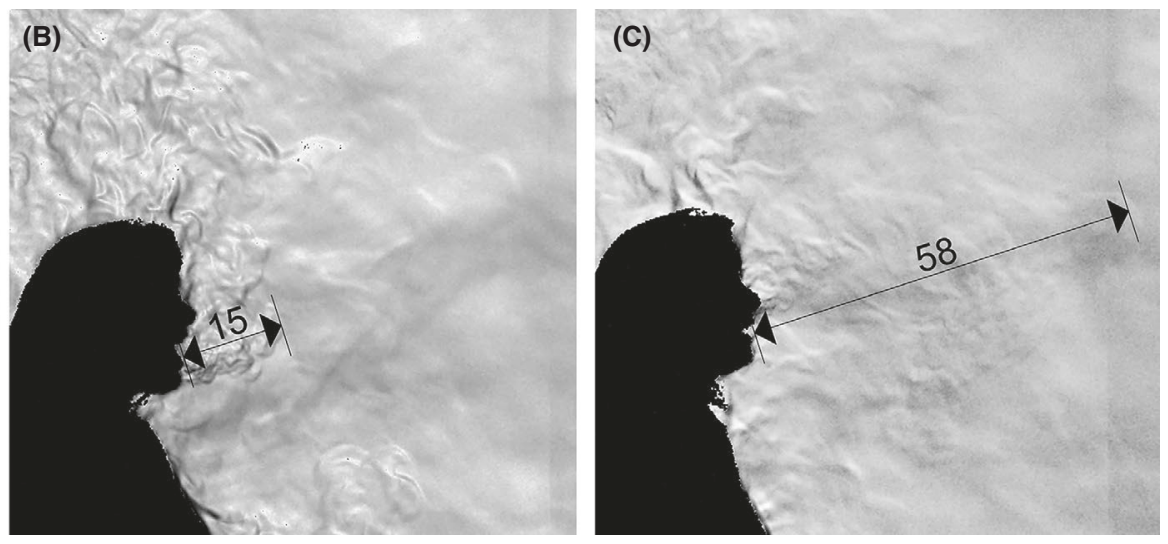
FIGURE 30 Maximal spreading distance of the breathing air from wind instruments and singers

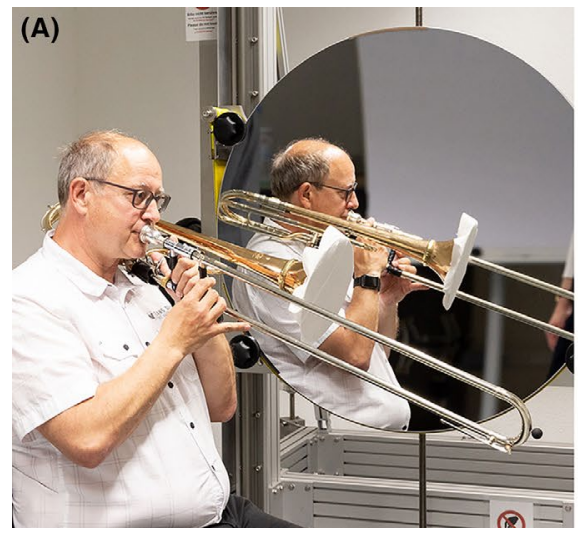

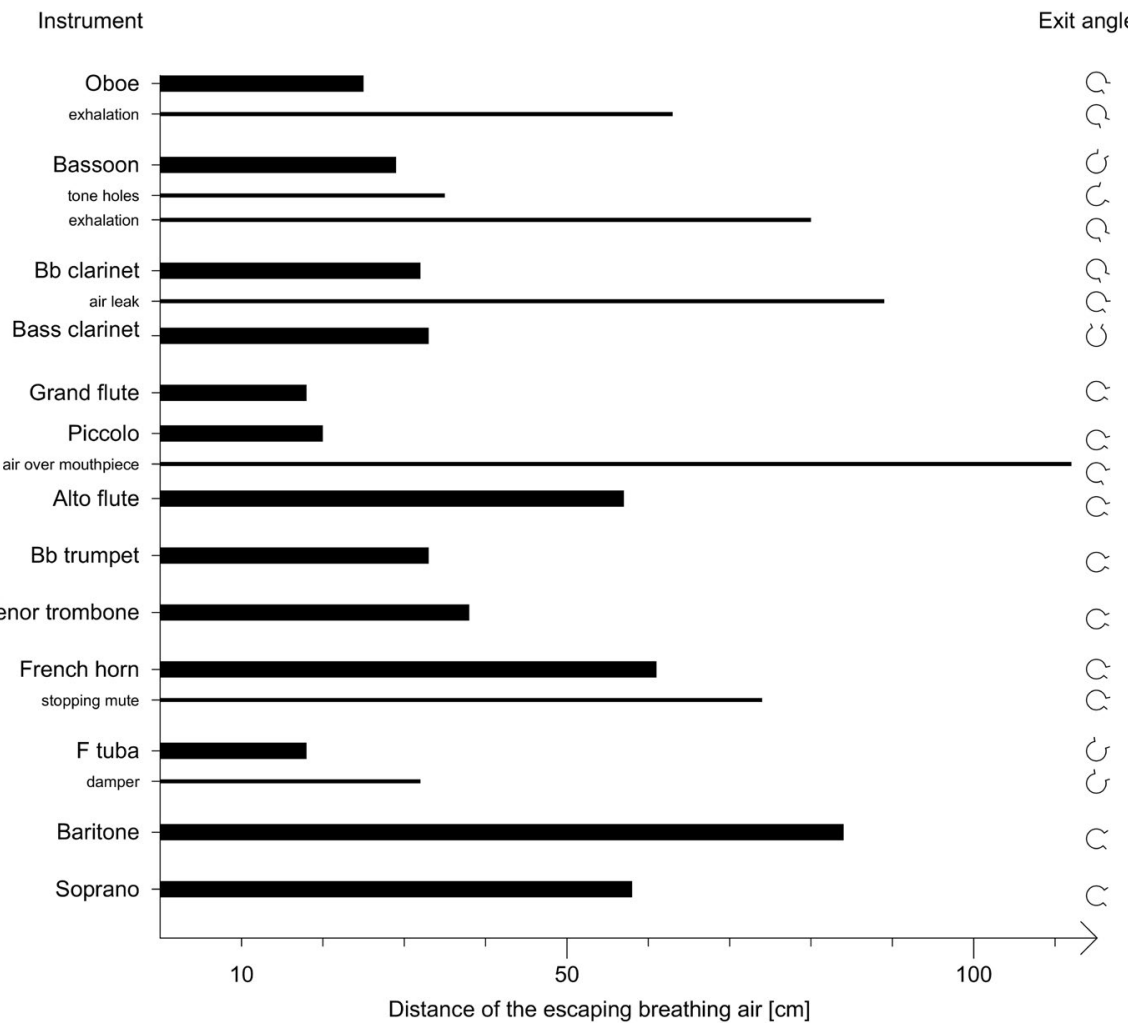
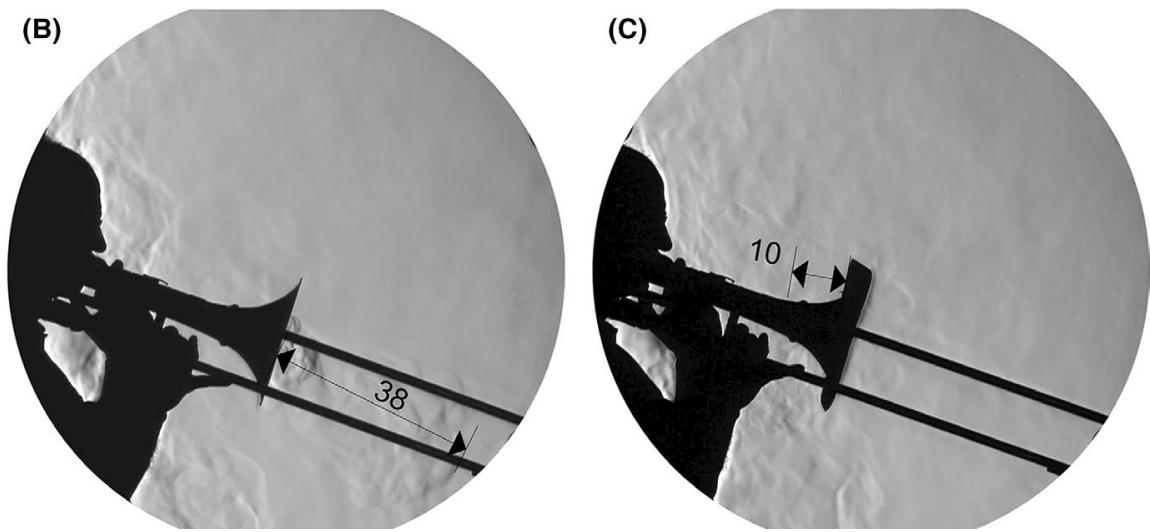

FIGURE 31 Trombone player with filter in front of the schlieren mirror (A), escaping breathing air while playing the tenor trombone without $(B)$ or with filter $(C)(\mathrm{cm})$

due to small movements of the surrounding air (e.g., due to the movements of fingers or hands when playing the instruments, air escaping from the tone holes, the musicians taking a breath between phrases, convective flows in the room, etc.). Furthermore, the measurements show that some of the measured velocities (e.g., oboe, grand flute, $\mathrm{Bb}$ trumpet, tenor trombone, and $\mathrm{F}$ tuba) decrease initially with increasing distance, but then increase again. This may be due to the turbulent properties of the flow, which causes the velocity to vary due to the occurrence of small eddies. However, attention has to be paid when looking at the reliability of such small measured velocities.

To reduce the breathing air escaping from the bells, especially from the brass instruments, a simple filter can also be used. In this case, the filter consists of cellulose and is taped directly to the bell of the instrument (Figure 31A). This can be applied to every brass instrument because the breathing air fully escapes from the bell. For woodwind instruments, filters are not usable because the breathing air escapes not only from the bell but also from the tone holes and sometimes near the mouthpiece. As an outlook, Figure 31C shows the spread of the breathing air when playing the trombone with the filter attached to the bell. Compared to Figure 31B, where there is no barrier which could hamper the flow, the air spread is significantly restricted when using the filter.

Similar to the visualizations above, only the breathing air escaping from the bell can be visualized. Thus, the actual spread of infectious particles cannot be estimated. However, it can be assumed that the filter works similar to speaking or singing while wearing a mask, where most of the particles stick to its material and, therefore, cannot enter the surrounding room air. 

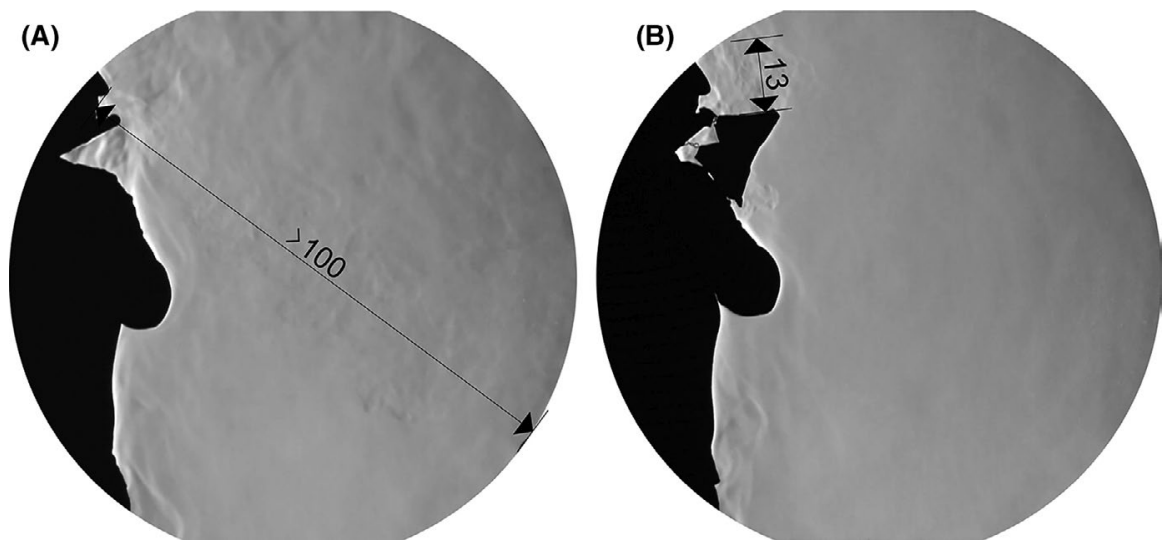

FIGURE 32 Range of the air blown over the mouthpiece of the grand flute without (A) and with filter (B)

An exception to apply a filter to woodwind instruments are flutes. The visualizations in Figure 15 showed that most of the breathing air is blown over the mouthpiece of the flutes. Hence, a filter can be placed in front of the mouthpiece to reduce the spread of the breathing air drastically (Figure 32).

According to the participating professional musicians, there are only slight differences in the sound when playing brass instruments with a filter. However, the tone appears slightly dull. Hardly any difference in the sound experience can be perceived when playing the flute with the filter attached to the mouthpiece.

\section{5 | CONCLUSION AND LIMITATIONS}

The results presented in this article show the spread of the breathing air when playing wind instruments and singing. The results contribute to estimating the range of potentially infectious breathing air, which is essential during critical health periods such as the current COVID-19 pandemic. To visualize the escaping breathing air, the optical schlieren imaging system as well as the background-oriented schlieren (BOS) technique were used. However, these methods only visualize refractive index gradients that occur due to density gradients in transparent media. If the density gradients (i.e., differences in temperature or pressure) become too small, neither the schlieren imaging nor the BOS method can visualize these gradients. This could occur, for example, due to air entrainment. However, during the studies presented in this article, the range of the escaping airflow was validated using hot-wire anemometry. Furthermore, the schlieren imaging and BOS method do not show the spread of small droplets or aerosols, which can contain pathogens. Therefore, the results can only be used to determine the direction of the expelled particles and to estimate how far larger droplets with a size of approximately $100 \mu \mathrm{m}$ could be transported with the expelled air to define distance rules.

In the measurements shown above, the spread of the breathing air from only professional musicians and classical trained singers was investigated. However, musicians who are still learning how to play an instrument or how to sing may induce different spreading patterns of the exhaled air. As they may leak additional air near the mouthpiece of the played instrument or exhale more air than needed when singing, a larger amount of potentially infectious breathing air may spread into the room.

Another limitation of this study was the constant movement of the players during the velocity measurements even though they were asked to remain as still as possible. This affects the distance between the sensors and the bell or the mouth. Moreover, the movement of the musician and their instrument can increase the measured value. The velocity measurements showed that the breathing air escapes only at small velocities from the bell of the wind instrument. Here, differences can be observed within the diameter of the bell and the respiratory pressure with which the instrument is played. For the air escaping from the mouth (exhaling when playing the oboe or bassoon and singing) and the air leaking near the mouthpiece (clarinet and bass clarinet), the air escapes at a higher velocity up to $v \approx 0.15 \mathrm{~m} / \mathrm{s}$.

Using the visualizations and findings discussed in this article, the range, dimensions, and velocities of the escaping breathing air can be estimated. In addition to possible future investigation of the viral load of the escaping air, a holistic understanding of the possible risk posed by wind instruments and singers can be obtained.

\section{ACKNOWLEDGMENTS}

The authors kindly acknowledge the commitment of the chief conductor and the wind players from the philharmonic orchestra Thüringen Philharmonie Gotha--Eisenach as well as the orchestra director, the wind players, and singers from the Deutsches Nationaltheater und Staatskapelle Weimar. We also thank the German Research Foundation DFG (Grant no. 444059583) for funding this project. Their support is highly appreciated.

\section{CONFLICT OF INTEREST}

The authors declare that they have no known competing financial interests or personal relationships that could have appeared to influence the work reported in this paper.

\section{AUTHOR CONTRIBUTIONS}

Lia Becher contributed to the conceptualization, investigation, project administration, and writing of the original draft preparation. Amayu W. Gena and Hayder Alsaad: investigation, writing, review, and editing. Bernhard Richter and Claudia Spahn: resources, writing, 
review, and editing. Conrad Voelker: supervision, writing, review, and editing.

\section{ORCID}

Lia Becher (D) https://orcid.org/0000-0001-8610-0958

Amayu W. Gena (D) https://orcid.org/0000-0002-0812-3801

Hayder Alsaad (D) https://orcid.org/0000-0001-7738-0193

Bernhard Richter (D) https://orcid.org/0000-0003-1497-559X

Claudia Spahn (D) https://orcid.org/0000-0002-0360-696X

Conrad Voelker (D) https://orcid.org/0000-0002-3687-0177

\section{REFERENCES}

1. Charlotte N. High rate of SARS-CoV-2 transmission due to choir practice in France at the beginning of the COVID-19 pandemic. $J$ Voice. 2020. https://doi.org/10.1016/j.jvoice.2020.11.029

2. Naunheim MR, Bock J, Doucette PA, et al. Safer singing during the SARS-CoV-2 pandemic: what we know and what we don't. J Voice. 2020. https://doi.org/10.1016/j.jvoice.2020.06.028

3. Muerbe D, Fleischer M, Lange J, Rotheudt H, Kriegel M. Aerosol emission is increased in professional singing. [DepositOnce Preprint]; 2020.

4. Asadi S, Wexler AS, Cappa CD, Barreda S, Bouvier NM, Ristenpart WD. Aerosol emission and superemission during human speech increase with voice loudness. Sci Rep. 2019;9:2348.

5. Echternach M, Gantner S, Peters G, et al. Impulse dispersion of aerosols during singing and speaking; [MedRxive Preprint] 2020.

6. Mürbe D, Kriegel M, Lange J, Schumann L, Hartmann A, Fleischer $M$. Aerosol emission of adolescents voices during speaking, singing and shouting. PLoS One. 2021;16(2):e0246819.

7. Ji Y, Qian H, Ye J, Zheng X. The impact of ambient humidity on the evaporation and dispersion of exhaled breathing droplets: a numerical investigation. J Aerosol Sci. 2018;115:164-172.

8. Stadnytskyi $\mathrm{V}, \mathrm{Bax} \mathrm{CE}, \mathrm{Bax} \mathrm{A}$, Anfinrud P. The airborne lifetime of small speech droplets and their potential importance in SARSCoV-2 transmission. Proc Natl Acad Sci USA. 2020;117:11875-11877.

9. Wei J, Li Y. Enhanced spread of expiratory droplets by turbulence in a cough jet. Build Environ. 2015;93:86-96.

10. Wilson NM, Norton A, Young FP, Collins DW. Airborne transmission of severe acute respiratory syndrome coronavirus- 2 to healthcare workers: a narrative review. Anaesthesia. 2020;75:1086-1095.

11. Kaehler CJ, Hain R. Singing in choirs and making music with wind instruments - Is that safe during the SARS-CoV-2 pandemic? University of the Bundeswehr Munich, Germany; 2020.

12. Richter B, Echternach M, Traser L, Burdumy M, Spahn C. The Voice - Insights into the Physiology of Singing and Speaking [DVD-ROM and App]. Esslingen am Neckar: Helbling; 2017.

13. Spahn C, Hipp A, Schubert B, et al. Airflow and air velocity measurements while playing wind instruments, with respect to risk assessment of a SARS-CoV-2 infection; [MedRxive Preprint] 2020.

14. Nusseck M, Richter B, Holtmeier L, Skala D, Spahn C. $\mathrm{CO}_{2}$ measurements in instrumental and vocal closed room settings as a risk reducing measure for a Coronavirus infection; [MedRxive Preprint] 2020.
15. Alsaad H, Voelker C. Qualitative evaluation of the flow supplied by personalized ventilation using schlieren imaging and thermography. Build Environ. 2020;167:106450.

16. Tang JW, Liebner TJ, Craven BA, Settles GS. A schlieren optical study of the human cough with and without wearing masks for aerosol infection control. J R Soc Interface. 2009;6(Suppl 6):727-736

17. Tang JW, Nicolle AD, Klettner CA, et al. Airflow dynamics of human jets: sneezing and breathing - potential sources of infectious aerosols. PLoS One. 2013;8(4):e59970.

18. Xu C, Nielsen PV, Liu L, Jensen RL, Gong G. Human exhalation characterization with the aid of schlieren imaging technique. Build Environ. 2017;112:190-199.

19. Tang JW, Noakes CJ, Nielsen PV, et al. Observing and quantifying airflows in the infection control of aerosol- and airbornetransmitted diseases: an overview of approaches. J Hosp Infect. 2011;77:213-222.

20. Gena AW, Voelker C, Settles GS. Qualitative and quantitative schlieren optical measurement of the human thermal plume. Indoor Air. 2020;30(4):757-766.

21. Meier GEA, inventor. Hintergrund-Schlierenmeßverfahren. DE 19942856 A1.

22. Mizukaki T, Wakabayashi K, Matsumura T, Nakayama K. Background-oriented schlieren with natural background for quantitative visualization of open-air explosions. Shock Waves. 2014;24:69-78.

23. Bauknecht A, Ewers B, Wolf C, Leopold F, Yin J, Raffel M. Threedimensional reconstruction of helicopter blade-tip vortices using a multi-camera BOS system. Exp Fluids. 2015;56:381.

24. Nicolas F, Todoroff $\mathrm{V}$, Plyer A, et al. A direct approach for instantaneous 3D density field reconstruction from background-oriented Schlieren (BOS) measurements. Exp Fluids. 2016;57:1.

25. Mazumdar A. Principles and Techniques of Schlieren Imaging Systems. Columbia University Computer Science Technical Reports; 2013.

26. Settles GS. Schlieren and Shadowgraph Techniques: Visualizing Phenomena in Transparent Media. Berlin Heidelberg: SpringerVerlag; 2001.

27. Becher L, Voelker C, Rodehorst V, Kuhne M. Background-oriented schlieren technique for two-dimensional visualization of convective indoor air flows. Opt Lasers Eng. 2020;134:106282.

28. Spahn C, Richter B, Poeppe J, Echternach M. Physiological Insights for Players of Wind Instruments [DVD-ROM]. Innsbruck - Esslingen - Bern-Belp: Helbling; 2013.

How to cite this article: Becher L, Gena AW, Alsaad H, Richter $B$, Spahn C, Voelker C. The spread of breathing air from wind instruments and singers using schlieren techniques. Indoor Air. 2021;31:1798-1814. https://doi.org/10.1111/ina.12869 